\title{
The role of the epithelial cell in Escherichia coli induced neutrophil migration into the urinary tract
}

\author{
W.W. Agace
}

\begin{abstract}
The role of the epithelial cell in Escherichia coli induced neutrophil migration into the urinary tract. W.W. Agace. (CERS Journals Ltd 1996.

ABSTRACT: Neutrophil influx to mucosal surfaces represents one of the earliest inflammatory responses to mucosal infection. We have been studying external interactions with urinary tract epithelial cells in an attempt to understand the molecular mechanisms behind this process.

Uropathogenic Escherichia coli induced urinary tract epithelial cells to secrete the neutrophil chemoattractant interleukin-8 (IL-8). IL-8 secretion was higher in response to isogenic strains expressing type 1 or $P$ fimbriae that adhered to the epithelial surface. Deliberate colonization of the human urinary tract with $E$. coli induced the local production of IL-8 and levels correlated with urinary neutrophil numbers suggesting a role for IL-8 in neutrophil migration. $E$. coli induced neutrophil migration across urinary tract epithelial layers in vitro, and this process was blocked with anti-IL-8 antibody. IL-8's activity was localized to the epithelial surface. Furthermore, these cells were shown to constitutively express IL-8 receptor A and B messenger ribonucleic acid (mRNA), suggesting a possible role for IL-8 on epithelial cell function. $E$. coli enhanced the expression of intercellular adhesion molecule-1 (ICAM-1) on urinary tract epithelial cells, and neutrophil migration across urinary tract epithelial layers in vitro was dependent on epithelial ICAM-1 and neutrophil Mac-1 (CD11b/CD18) expression.

These results suggest that bacterial/epithelial cell interactions play a key role in the induction of neutrophil migration during mucosal infection, and show the necessity for host-derived chemotactic factors and cell adhesion events in $E$. coli induced transuroepithelial migration in vitro.

Eur Respir J., 1996, 9, 1713-1728.
\end{abstract}

\author{
Correspondence: W.W. Agace \\ Department of Medical Microbiology \\ Section of Clinical Immunology \\ Lund University \\ Lund \\ Sweden
}

Keywords: Cell adhesion molecules chemokines

epithelial cells

mucosal

neutrophils

Received: February 11996

Accepted for publication February 101996

These studies were supported by the following grants: a Swedish Medical Research Council Scholarship in the area of Mucosal Immunology, The Lund University Medical Faculty, the Swedish Medical Research Council, the Österlund, Crafoord and Lundberg foundations and the Royal Physiographic Society.
Mucosal surfaces form barriers that prevent microbes from reaching internal organs. The antimicrobial defence of the mucosa is achieved through the co-ordinated action of innate and specific immune mechanisms. Despite this, the large majority of infections start at mucosal sites.

Neutrophil migration to the lung, the urinary and the intestinal tract occurs as part of the initial inflammatory response to mucosal bacterial infection. This process involves neutrophil adherence to the endothelial blood vessel wall and extravasation into the lamina propria. Finally, neutrophils must cross a basement membrane and epithelial layer into the luminal space. There is little information regarding the mechanisms of bacterial induced neutrophil migration to sites of mucosal infection, the resident mucosal cells involved in this response, and the chemotactic signals released by the mucosa at the onset of infection.

This review focuses on the importance of bacterial-epithelial interactions in the induction of neutrophil influx at the onset of urinary tract infection (UTI). The first part briefly reviews some of the cell adhesion molecules and chemotactic signals involved in neutrophil extravasation, whilst the second part examines the role of bacterial-epithelial interactions in the induction of neutrophil migration to the mucosa and some of the molecular mechanisms involved in this response.

\section{Neutrophil extravasation}

The first stage in neutrophil migration to sites of mucosal infection involves neutrophil migration across the endothelial vessel wall. Neutrophil migration from the vasculature occurs mainly through postcapillary venules or capillary beds. This migration is controlled by specific cell adhesion molecules on the neutrophil and endothelial surface, that are upregulated at sites of inflammation. The initial interaction between the neutrophil and endothelial vessel wall is mediated through selectin/ligand interactions and results in neutrophil rolling across the endothelial surface. Rolling is unlikely to occur in the capillary beds, since the smaller diameter of the capillary segments forces neutrophil deformation whilst passing through these vessels. Rolling is followed by tight adhesion, mediated by $\beta_{2}$ integrins on the neutrophil surface and intercellular adhesion molecules (ICAMs) on the endothelial surface. Chemoattractants are thought to play an important role in this second stage of adhesion by upregulating the avidity of $\beta_{2}$ integrins for their ligands and increasing $\beta_{2}$ integrin expression on the neutrophil surface. Such interactions result in a flattening of the neutrophil on the endothelial vessel surface. The mechanism of transendothelial migration is less well understood but is thought to require homologous binding of 
platelet endothelial cell adhesion molecule-1 (CD31, PECAM-1) [1]. This molecule is a member of the immunoglobulin superfamily expressed on neutrophils and endothelial cells [2-4]. The majority of PECAM-1 on endothelial cells is concentrated to the endothelial intercellular junctions; however, approximately $15 \%$ is expressed on the apical surface. suggesting the existence of an apical-basal gradient through the intercellular junction. Anti-PECAM antibody inhibits transendothelial migration without interfering with the ability of the leucocytes to remain adherent to the apical surface of the endothelial cells.

\section{Selectins}

Selectins are involved in the initial event in neutrophil recruitment by mediating neutrophil rolling along endothelial vessel walls [5-7]. The selectin family of cell adhesion molecules consists so far of three members: Lselectin (lectin adhesion molecule-1 (LECAM-1), Leu 8), P-selectin (CD62), and E-selectin (CD62E, endothelial leucocyte adhesion molecule-1 (ELAM-1)).

These three selectins are C-type lectins, requiring calcium for their receptor-binding activity. E-selectin, $\mathrm{P}$-selectin and L-selectin all bind to sialylated, fucosylated lactosamine structures, notably sialyl Lewis $\mathrm{x}\left(\mathrm{sLe}^{\mathrm{x}}\right)$ and sialyl Lewis a, an isomer of sLe ${ }^{\mathrm{x}}$, expressed on glycoproteins $[8,9]$. L- and P-selectin have also been shown to interact with a wide number of sulphated polysaccharides, such as heparin, fucoidan and sulphatides (reviewed in [9]).

$\mathrm{P}$-selectin is associated with $\alpha$ granules in resting platelets and Weibel-Palade bodies in endothelial cells $[10,11]$. It is rapidly and transiently expressed on the endothelial cell surface when these cells degranulate upon activation. In vitro stimulation of endothelial cells with thrombin or histamine induces a rapid expression of P-selectin, which peaks at $5 \mathrm{~min}$ and is largely absent by $20 \mathrm{~min}$ [10-12]. Neutrophil adhesion to P-selectin does not require neutrophil metabolism but is dependent on extracellular calcium [13]. Whilst P-selectin itself appears incapable of inducing a signal to attaching neutrophils, a juxtacrine stimulation with endothelial associated platelet-activating factor (PAF) results in activation of surface $\beta_{2}$ integrins on the neutrophil surface and their high affinity binding to endothelial ligand [14]. In vivo, neutrophil migration into the peritoneum, in response to Streptococcus pneumoniae is severely impaired in P-selectin knockout mice, whilst migration into the lung in response to $S$. pneumoniae is not effected [15].

E-selectin is expressed by endothelial cells after stimulation with proinflammatory cytokines, such as interleukin (IL)-1 and tumour necrosis factor (TNF), and requires de nova protein synthesis. Levels of E-selectin peak after 4-6 h stimulation and decline to baseline levels by 24-48 $\mathrm{h}$ in vitro $[16,17]$. In contrast to P-selectin, E-selectin binding to neutrophils directly activates integrin molecules on the neutrophil surface [18]. In vivo, anti-E-selectin antibody blocks neutrophil dependent immunoglobulin $\mathrm{G}(\mathrm{IgG})$ immune complex-induced damage in rats and neutrophil extravasation during antigen-induced acute airway inflammation and late phase airway obstruction in monkeys $[19,20]$.
L-selectin is constitutively expressed and functional on unactivated neutrophils. Its mediation of neutrophil rolling on activated endothelium occurs through an undefined inducible ligand [21]. L-selectin is rapidly shed upon neutrophil activation with chemotactic stimuli by proteolytic cleavage near the transmembrane domain [22, 23]. Cross-linking of L-selectin with monoclonal antibodies induces a rapid and transient increase in intracellular calcium and superoxide ions and an upregulation of surface $\beta_{2}$ integrin expression in neutrophils [24]. In vivo, anti-L-selectin antibody reduced neutrophil-mediated lung injury [25], and a soluble immunoglobulin chimera containing the murine L-selectin extracellular domain significantly decreased the number of neutrophils migrating to the peritoneum in response to the inflammatory irritant thioglycollate [26].

\section{Integrins}

Members of the integrin family are involved in the tight adhesion of neutrophils to the endothelial surface, that occurs subsequent to selectin/ligand mediated neutrophil rolling, and also in neutrophil migration through extracellular matrices. Integrins are transmembrane glycoproteins, each composed of an $\alpha$ subunit noncovalently associated with a $\beta$ chain to form a heterodimer. The integrin $\alpha$ chain subunits form two groups based upon structural differences. One group is cleaved during synthesis to form one heavy and one light chain, that remain associated via a single disulphide linkage. The other group contains an inserted domain (I domain) that is thought to be involved in receptor-binding. Fourteen $\alpha$ and eight $\beta$ subunits have been characterized so far, which in various combinations make at least 20 known integrins.

The integrins principally involved in neutrophil interactions with endothelial cells belong to the $\beta_{2}$ family [27-29]. The three members of this family share a common $\beta$ subunit (CD18) that is associated with three different $\alpha$ subunits $\alpha_{L}, \alpha_{M}$, and $\alpha_{X}(C D 11 a, b$ and $c)$. All three integrins are expressed on the neutrophil surface, the predominant form being CD11b/CD18 (Mac-1). Mac-1 and CD11a/CD18 (leucocyte function associated antigen-1 (LFA-1)) receptors on endothelial cells are members of the immunoglobulin superfamily (see below), whilst endothelial receptors for CD11c/CD18 have not yet been identified [29].

Mac-1 and CD11c/CD18 but not LFA-1 are also found in intracellular storage pools within neutrophils [30-32]. The majority of Mac-1 $(75 \%)$ in resting neutrophils is localized in specific granules, the remainder being stored in secretory vesicles and plasma membranes [33]. Activation of neutrophils with many agonists, including chemotactic agents, results in a translocation of integrin molecules from the intracellular stores predominantly from secretory vesicles, to the neutrophil plasma membrane.

Activation of neutrophils also induces an increase in the avidity of expressed integrin for its receptor(s). It is this increased avidity and not de novo expressed integrin that results in the initial increased adhesion of neutrophils to activated endothelial cells [34]. De novo expressed integrin may, however, be utilized for subsequent locomotion events following further increases in 
stimulus concentration [35]. The regulation of $\beta_{2}$ integrin avidity is not fully understood but is a rapidly reversible event thought to involve the cytoplasmic domain of the integrins $\beta$ chain $[36,37]$. The continuous modulation of integrins from low to high avidity state and vice versa appears vital for cell migration [38].

The importance of $\beta_{2}$ integrins is best demonstrated in patients suffering from the rare leucocyte adhesion deficiency (LAD) disorder. These patients suffer poor wound healing and recurrent, often fatal, bacterial infections as a result of deficient or much reduced expression of the common $\beta_{2}$ subunit CD18. This is associated with an inability of their phagocytes to adhere to endothelium and migrate to sites of infection. Studies in animal models have shown neutrophil migration in response to bacterial infection to be CD18-dependent or CD18independent, depending on the site of infection and the bacterial stimulus. Anti-CD18 antibody blocked neutrophil migration in response to intraperitoneal and intrabroncheal instillation of Escherichia coli, and intraperitonial instillation of $S$. pneumoniae. In contrast neutrophil migration in response to intrabroncheal instillation of $S$. pneumoniae was CD18-independent [39]. Furthermore, neutrophil migration into the peritoneum in response to Salmonella typhimurium was CD18-dependent, but CD18-independent in response to Listeria monocytogenes [40]. Whilst the mechanism of CD18-independent neutrophil migration remains to be defined, these results indicate the level of complexity involved in neutrophil migration to sites of bacterial infection.

\section{Immunoglobulin superfamily}

Two members of the immunoglobulin superfamily, intercellular adhesion molecule-1 and intercellular adhesion molecule-2 (ICAM-1, ICAM-2) act as endothelial receptors for the neutrophil $\beta_{2}$ integrins. Whilst ICAM-1 is constitutively expressed by a wide variety of cells in addition to endothelial cells, the tissue distribution of ICAM-2 appears to be restricted to blood vessel endothelium and some lymphoid cells [41]. ICAM-1 (CD54) consists of five immunoglobulin (Ig)-like domains, with the LFA-1 binding site located at the $\mathrm{N}$ terminal domain (domain 1) and the Mac-1 binding site located within the 3rd Ig-like domain [42, 43]. Endothelial ICAM-1 expression increases after stimulation with proinflammatory cytokines, such as IL-1 and TNF, reaching maximal levels after $24 \mathrm{~h}$. This increase in expression requires de novo protein synthesis [17].

ICAM-2 contains two Ig-like domains that are most homologous with the two N terminal domains of ICAM-1, and has binding sites for LFA-1 and Mac-1 [44, 45]. In contrast to ICAM-1, ICAM-2 expression is not enhanced following stimulation with proinflammatory cytokines $[41,46]$. The inducibility of ICAM-1 and constitutive expression of ICAM-2 by endothelial cells suggests that ICAM-1 may be the relevant endothelial ligand for $\beta_{2}$ integrins during an inflammatory response, while ICAM-2 may be of more relative importance in the unstimulated state or early on during a response before ICAM-1 expression is increased. In vivo, anti-ICAM-1 antibody inhibits neutrophil-dependent lung vascular injury that occurs after occlusion and reperfusion, intravenous infusion of cobra venom factor, or after deposition of $\mathrm{IgG}$ and $\operatorname{IgA}$ immune complexes [47-49]. ICAM-1 knockout mice show reduced neutrophil migration to the peritoneum in response to sterile inflammatory stimuli [50], and are resistant to high-dose endotoxin lethal shock [51]. Resistance is associated with a significant decrease in neutrophil infiltration into the liver at $24 \mathrm{~h}$. The role of ICAM-2 in neutrophil migration in vivo has not been studied.

\section{Chemokines}

Neutrophil migration from the vasculature to the mucosal surface is likely to occur in response to chemoattractants and inflammatory mediators released from the site of infection. While numerous chemotactic molecules have been described, recent evidence has indicated a key role for the chemotactic cytokine family (chemokines) in leucocyte migration. Chemokines are a relatively new and expanding group of low MW (8-10 kDa) cytokines, that are able to attract and activate leucocytes (for review see [52]).

Each member of the chemokine group contains two internal disulphide loops and four conserved cysteine residues. The positioning of the first two cysteines provides the basis for the division of the chemokine family into two subgroups. Members of the $\alpha$ chemokine (CXC) group contain a single amino acid insert between the first two cysteines, which in the $\beta$ chemokine (CC) group are adjacent. Members of the $\alpha$ chemokine group include IL-8, neutrophil-activating protein-2 (NAP-2), platelet factor-4 (PF-4), connective tissue-activated peptide III (CTAP-III), epithelial cell neutrophil-activating protein-78 (ENA-78), Gro- $\alpha$, Gro- $\beta$, Gro- $\gamma$. Most of these chemokines act as chemotactic and activating agents for neutrophils, inducing cytosolic free calcium changes, chemotaxis, shape changes and exocytosis. A major determinant of activity towards neutrophils is the necessity for the GluLeu-Arg (ELR) motif preceding the first cysteine in the $\mathrm{N}$-terminal domain [53]. Members of the $\beta$ chemokine group include monocyte chemoattractant protein 1,2 and 3 (MCP-1, MCP-2 and MCP-3), macrophage inflammatory protein- $1 \alpha$ and $1 \beta$ (MIP- $1 \alpha$ MIP-1 $\beta$ ) and "regulated upon activation in normal T-cells, expressed and secreted" (RANTES). None of these, with the possible exception of MIP-1 $\alpha$, show stimulation for neutrophils but they are all potent activators of monocytes (for review see [52]).

\section{Interleukin-8}

IL- 8 is the best characterized member of the $\alpha$ chemokine group. IL- 8 is produced by most cells in response to inflammatory stimuli, such as IL- $1 \alpha$, IL-1 $\beta$, TNF- $\alpha$, immune complexes and bacteria (for review see [52]). The unglycosylated protein is secreted after cleavage of a 20 amino acid signal sequence [54]. Further $\mathrm{N}$ terminal processing yields numerous biologically active truncation analogues ranging in size from 69-79 amino acids in length $[54,55]$. Processing requires protease release by the cells and appears to be cell-specific, since some cells (human umbilical vein endothelial cells (HUVEC) and fibroblasts) predominantly produce the 77 amino acid protein, while others (monocytes and macrophages) 
produce both the 77 and 72 amino acid protein [54, 5659]. Interestingly, the potency of IL- 8 has been shown to increase with progressive $\mathrm{N}$ terminal cleavage [60]. IL-8 exists as a noncovalently bound homodimer in concentrated form or upon crystallization [61, 62]. However, IL-8 exists as a monomer at physiologically relevant concentrations in vitro, and the monomeric form is sufficient for receptor-binding and full in vitro biological activity [63, 64].

The in vitro biological activities of IL-8 on neutrophils include integrin receptor upregulation and increased avidity, chemotaxis, shape change degranulation, and formation of bioactive lipids [65-70]. The role of IL-8 in neutrophil chemotaxis appears complex. In vitro IL-8 can mediate neutrophil chemotaxis through numerous extracellular matrices, including fibrin gels, matrigel (reconstituted basement membrane proteins), fibronectin, fibrinogen and collagen IV [71]. In addition, endogenous IL-8 secreted by stimulated endothelial layers is required for neutrophil migration across endothelial vessel walls [72]. In vivo, intradermal injection of IL-8 was shown to induce a rapid and long-lasting neutrophil influx in rabbits [73, 74]. The maximum rate of neutrophil migration was reached within $30 \mathrm{~min}$ and remained

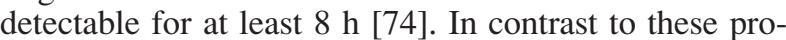
inflammatory effects of IL-8, GimBrone et al. [57] reported that exogenous IL-8 inhibited neutrophil adherence to lipopolysaccharide (LPS)-activated HUVEC cells. Recent studies have shown that intravascular IL-8 inhibits extravasation in vivo. Human IL-8 transgenic mice, that have elevated serum IL-8 levels, and animals injected intravenously with IL-8 have impaired neutrophil migration extravascularly $[75,76]$. The mechanism behind the leucocyte adhesion inhibition (LAI) activity of IL-8 is unknown; however, its effects appear to be localized to the neutrophil and not the endothelial cell surface. IL-8 induced shedding of L-selectin has been proposed to play a role by preventing activated neutrophils from initiating the rolling event [77]. This is not likely to be the whole story, since IL-8 when delivered intravenously decreased the migratory capacity of rabbit neutrophils without inducing a significant loss of L-selectin [78]. The LAI activity of IL-8 may be related to its ability to cause rapid changes in the confirmation of neutrophil actin microfilaments [79].

Since soluble IL-8 prevents neutrophil adhesion to the endothelial surface, a model for chemokine-induced neutrophil migration involving an attractant gradient bound to the endothelial surface has been proposed [80, 81]. IL- 8 binds to the surface of postcapillary venules in vivo and to extracellular matrix proteins, endothelial cells, keratinocytes and dermal cells, suggesting that a cellbound IL-8 gradient could potentially be set up from inflammatory loci [82-84].

\section{IL-8 receptors}

Early binding studies of IL-8 to human neutrophils indicated the presence of two high affinity IL- 8 receptors [85]. Molecular cloning has identified both IL-8 receptors (IL-8RA and IL-8RB) as members of the seven transmembrane guanine-nucleotide-binding $(\mathrm{G})$ protein linked receptor family $[86,87]$. IL-8RB, but not IL-8RA, also has high affinity for other members of the $\alpha$ chemokine family, including NAP-2, Gro, and melanoma growthstimulating activator (MGSA) [88]. These two receptors share $77 \%$ amino acid sequence homology; however, they have low amino acid identity at their amino terminus, which is thought to be involved in receptor subtype specificity $[86,87,89]$. Subsequent studies have shown that many cell types, in addition to neutrophils, including T-cell populations, basophils, endothelial cells, monocytes and fibroblasts, express transcripts for one or both IL-8 receptors (for reviews see [52, 90]).

The development of monoclonal antibodies specific for each receptor has led to some initial observations regarding their relative importance in neutrophil migration. A recent study, examining IL-8 receptor internalization rates upon binding with ligand, showed IL-8RB to have a $2-5$ fold higher affinity for IL-8 than IL-8RA on human neutrophils. Binding of IL- 8 to both receptors resulted in ligand internalization, degradation of IL-8 and reappearance of receptor on the cell surface [91]. Receptor reappearance for IL-8RA was rapid (100\% within $90 \mathrm{~min}$ ), whilst reappearance for IL-8RB was slow (40\% within $180 \mathrm{~min}$ ). At sites distant from the inflammatory loci, where IL- 8 concentrations are likely to be at their lowest, IL-8RB may receive the IL-8 signal first and initiate neutrophil migration. IL-8RA, since it reappears on the neutrophil surface quicker than IL-8RB, may mediate the IL- 8 signal as the neutrophils approach the site of inflammation. In a further in vitro study, blocking of IL- 8 binding to either IL-8RA or IL-8RB differentially effected IL-8-induced neutrophil chemotaxis. Monoclonal anti-IL-8RA antibody blocked the majority of IL-8-induced neutrophil chemotaxis, whilst only a minor portion of chemotaxis was blocked with antibodies to IL-8RB. In contrast neutrophil migration in response to Gro- $\alpha$ was blocked with antibody to IL-8RB but not IL-8RA [92]. These results indicate that IL-8RA may be the important neutrophil IL-8 receptor in IL- 8 mediated chemotaxis.

Other receptors for IL-8 include the duffy antigen and proteoglycans. The duffy antigen acts as a chemokine receptor on the surface of erythrocytes and is also expressed on kidney venules $[93,94]$. The in vivo role of this receptor is not known but IL-8 bound to erythrocytes is incapable of activating neutrophils, suggesting that erythrocytes may act as a sink for IL-8 by reducing the amount of soluble IL-8 in serum [95]. Chemokines, including IL-8, also bind to proteoglycans [81]. These are proteins that have been post-translationally modified by the addition of glycosaminoglycan side chains at serine residues. This results in the formation of highly charged molecules with long polysaccharide chains consisting of repeating disaccharide units. Proteoglycans are found at the endothelial surface and within the extracellular matrix, and have been proposed to play an important role in presenting chemokines to leucocytes [81]. Indeed, the activity of IL- 8 is enhanced when it is bound to heparan sulphate or heparin [96].

\section{Escherichia coli-epithelial interactions in the induction of neutrophil migration}

Infections of the urinary tract have provided a useful model in examining mechanisms of bacterially-induced 
mucosal inflammation. Uropathogenic E. coli become established in the host at a site outside the urinary tract (often the large intestine). The bacteria then spread via the vaginal and periurethral areas into the urinary tract and establish bacteriuria [97-99]. Once in the urinary tract, bacteria induce a rapid mucosal inflammatory response that includes the influx of large numbers of neutrophils into the urine [100, 101]. Indeed neutrophils in the urine (pyuria) has been used as a diagnostic parameter for UTI since the start of the century [102].

\section{E. coli interactions with urinary tract epithelial cells}

Since epithelial cells dominate the urinary mucosal surface and are the first cellular contact with mucosal pathogens, they have become a focus of attention as mediators of the mucosal inflammatory response to infection. The initial interaction of $E$. coli with urinary tract epithelial cells is mediated by specific fimbrial structures expressed on the bacterial surface. Most uropathogens express $\mathrm{P}$ and type 1 fimbriae. $\mathrm{P}$ fimbriae adhere to Gal $\alpha 1-4 \mathrm{Gal} \beta$ and GalNAc $\beta-3 \mathrm{Gal} \alpha 1-4 \mathrm{Gal} \beta$-containing oligosaccharide sequences in the globoseries of glycolipids that are present on epithelial and nonepithelial components of the urinary bladder and ureters, and are the dominating nonacid glycolipids on kidney tissue [103, 104]. Adherence is mediated by papG adhesins located at the fimbrial tip [105]. Several $G$ adhesins exist that all share specificity for the globoseries of glycolipids but differ in isoreceptor specificity, binding to epithelial cells, and disease association [106-110]. Type 1 fimbrial adherence is mediated by the FimH adhesin, located along the fimbrial shaft and at the fimbrial tip [111]. This adhesin recognizes terminally located D-mannose moieties on cell-bound and secreted glycoproteins [112-116]. In contrast to the papG adhesins, the deoxyribonucleic acid (DNA) sequences of FimH adhesins are highly homologous. Minor variations in these sequences may, however, result in different adherence phenotypes [117, 118]. While type 1 fimbriated bacteria bind to urinary tract epithelial cells, the identity of the type 1 receptors on the epithelial surface remain to be identified.

Early studies showed that urinary tract epithelial cell lines originating from the human bladder and kidney secreted IL-6 in response to uropathogenic E. coli [119]. The magnitude of this response was influenced by the properties of the bacterial strain [120]. The production of IL- 6 by bladder and kidney epithelial cell lines was higher in response to $\mathrm{P}$ and type 1 fimbriated strains than nonfimbriated isogens, and was associated with an increased adherence of these strains to the epithelial surface. Furthermore, co-incubation of urinary tract epithelial cell lines with D-threo-1-phenyl-2-decamoylamino-3-morpholino-1-propanol PDMP, a structural analogue of ceramide, depleted expression of the globoseries of glycolipids by these cells, resulting in an inability of $\mathrm{P}$ fimbriated $E$. coli to adhere to the epithelial surface. This led to a significant reduction in IL-6 secretion in response to P fimbriated but not type 1 fimbriated $E$. coli [121]. Together these results suggested that epithelial cells were playing an important role in the induction of mucosal inflammation, and that the properties of the bacterial pathogen may influence this response.

\section{Epithelial cell IL-8 production in response to $E$. coli}

To examine whether epithelial cells are involved in the induction of neutrophil migration during UTI, we determined whether these cells produced cytokines with chemotactic activity for neutrophils and whether E. coli could stimulate their production. We also compared the ability of E. coli strains expressing $\mathrm{P}$ and type 1 fimbriae to stimulate epithelial cytokine production.

Normal urinary tract epithelial cells isolated from bladder scrapings of patients undergoing cystoscopy for bladder neck obstruction stained for intracellular IL-8 after stimulation with E. coli (fig. 1) [122]. Furthermore, indirect immunofluorescence studies examining intracellular cytokine levels in bladder (J82) and kidney (A-498) epithelial cell lines showed that uropathogenic E. coli induced an increase in IL-8 producing cells, which peaked after $2 \mathrm{~h}$ stimulation and remained higher than controls at 6 and $24 \mathrm{~h}$ [123]. The production of IL- 8 by these cells in response to bacteria was accompanied by increased expression of IL-8 messenger ribonucleic acid (mRNA) [124].

The role of adherence in the induction of epithelial IL-8 responses was examined by stimulating epithelial cells with isogenic E. coli strains expressing either $\mathrm{P}$ or type 1 fimbriae (table 1) [122]. The increased IL-8 secretion was associated with increased bacterial adherence to the epithelial cell surface. IL-8 secretion by the bladder and kidney epithelial cell lines was greatest in response to the highly adherent type 1 fimbriated isogen. Furthermore, addition of $\alpha$-methyl-D-mannoside, a receptor analogue for the type 1 fimbrial adhesin, reduced type 1 mediated adherence and epithelial IL- 8 production. The $\mathrm{P}$ fimbriated isogen adhered only to the bladder epithelial cells and induced higher IL-8 secretion in these cells than the parent strain (table 1). The low adherence properties of this strain were due to its atypical P fimbrial adhesin. Subsequent studies have shown that E. coli strains expressing the major $\mathrm{P}$ fimbrial adhesin $\left(\mathrm{PapG}_{\mathrm{IA} 2}\right)$ associated with

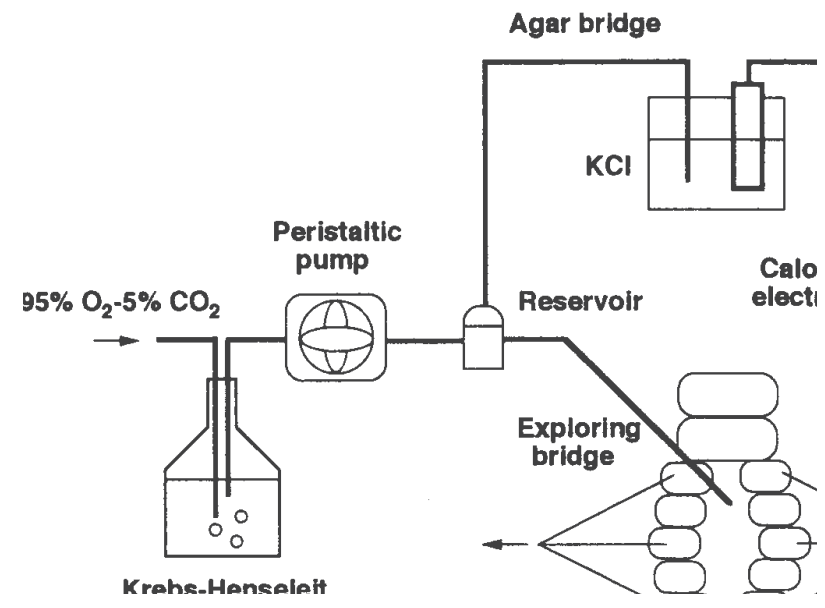

Fig. 1. - Intracellular staining of interleukin-8 in freshly isolated urinary tract epithelial cells after stimulation with $E$. coli. 
Table 1. - Secretion of interleukin-8 (IL-8) by urinary tract epithelial cells (kidney A-498 and bladder J82) after stimulation with isogenic strains of Escherichia coli

\begin{tabular}{llcc}
\hline Cell line & \multicolumn{1}{c}{ E. coli } & $\begin{array}{c}\text { Adherence } \\
\text { bacteria.cell }\end{array}$ & $\begin{array}{c}\mathrm{IL}-8 \\
\mathrm{ng} \cdot \mathrm{mL}^{-1}\end{array}$ \\
\hline A-498 & None & & 0.2 \\
& Nonfimbriated & 0.2 & 2.1 \\
& P fimbriated & 0.3 & 2 \\
& Type 1 fimbriated & 100 & 4.3 \\
J82 & None & & \\
& Nonfimbriated & 0.2 & 4.3 \\
& P fimbriated & 3.4 & 9 \\
& Type 1 fimbriated & 100 & 14.5 \\
\hline
\end{tabular}

Epithelial cells were stimulated for $24 \mathrm{~h}$ with E. coli $\left(10^{8}\right.$ bacteria $\left.\cdot \mathrm{mL}^{-1}\right)$.

severe UTI, bind well to urinary tract epithelial cells and induce higher levels of cytokine secretion in these cells than nonfimbriated isogens $[121,125]$.

These results represent early observations in the field of epithelial cytokine production in response to bacteria. $E$. coli had previously been shown to stimulate epithelial IL-6 secretion; however, the ability of epithelial cells to produce a range of cytokines, including neutrophil chemoattractants, in response to bacterial stimulation had not been recognized. Subsequent studies have confirmed that mucosal epithelial cells produce a specific range of proinflammatory cytokines in response to bacterial stimulation, and have shown the ability to secrete IL- 8 to be common to lung, intestinal, gastric and urinary tract epithelium (for review see [126]).

The mechanism of bacterial induced IL-8 production differs depending on the bacterial stimulant and origin of the epithelial cells. Several possibilities by which adherence and fimbrial expression enhances the urinary tract epithelial cytokine response have been suggested. Firstly, attachment may increase the concentration of bacterial products at the epithelial surface that activate cell cytokine responses. Secondly, fimbriae may directly activate the cells through fimbriae-receptor interactions. Adhesin positive P fimbriae have been shown to induce epithelial IL-6 production, albeit at lower levels than whole bacteria [120]. The ceramide signalling pathway was recently implicated in the epithelial IL- 6 response to $\mathrm{P}$ fimbriated $E$. coli. $\mathrm{P}$ fimbriated bacteria induced the release of free ceramide and the formation of ceramide1-phosphate in urinary tract epithelial cells [125]. IL-6 production was completely blocked by serine threonine kinase inhibitors. In contrast, serine threonine kinase inhibitors had no effect on epithelial IL-6 secretion in response to a type 1 fimbriated isogen. $\mathrm{P}$ and type $1 \mathrm{fim}-$ briated $E$. coli, therefore, stimulate epithelial IL-6 production via different intracellular pathways. Whether similar intracellular signals are involved in bacterialinduced IL- 8 production remains to be determined.

Bacterial adherence also enhances IL- 8 production in epithelial cells from other mucosal sites. Purified Pseudomonas pilin induces a dose-dependent IL-8 secretion, but at lower levels than whole bacteria. Furthermore the Pseudomonas flagellin, which may also serve as an adhesin for epithelial attachment, and a low molecular mass product suggested to be the Pseudomonas auto-inducer (PAI) stimulate epithelial IL-8 secretion [127, 128]. Bacterial invasion appears to be a prerequisite for the induction of IL- 8 by colon epithelial cells, since only invasive Salmonella, Shigella, Yersinia, Listeria and Escherichia species stimulate IL-8 production in these cells [129]. In contrast, low and highly adhesive Helicobacter pylori strains, soluble $H$. pylori extracts and concentrated $H$. pylori supernatants induce IL-8 production in gastric epithelial cell lines. Other Gram-negative organisms, including Pseudomonas aeruginosa and an E. coli strain that failed to induce IL-8 production in colon epithelial cells, also induce IL- 8 production in these cells [130, 131]. Common to all mucosal epithelial cells is their low responsiveness to LPS [120, 129, 132, 133]. It has been suggested that the poor epithelial response to LPS is due to a lack of CD14 expression by these cells. Indeed, addition of soluble CD14 has been reported to enhance epithelial sensitivity to LPS [134]. However, this has yet to be shown for urinary tract epithelial cells.

\section{Evidence of local IL-8 production during mucosal bacterial infection}

The production of IL- 8 by E. coli stimulated urinary tract epithelial cells suggested the possible involvement of IL-8 in the neutrophil influx during UTI. To examine whether $E$. coli stimulate IL-8 production in the human urinary tract, and the relationship between IL-8 and urinary neutrophil numbers, urine samples were collected from patients that had been deliberately colonized with E. coli in the urinary tract and measured for IL-8 [122].

Deliberate colonization of the urinary tract with nonvirulent strains of $E$. coli has been used as a treatment for patients suffering from recurrent UTI who are refractory to other therapy [135]. Three E. coli strains were used in the patient colonizations: a wild type $\mathrm{ABU}$ strain, which had been carried by a girl with asymptomatic bacteriuria for 3 yrs without deterioration of renal function (this strain did not express P or type 1 fimbriae); and two transformants containing the pil DNA sequences encoding type 1 fimbriae and the papJ96 DNA sequences encoding $\mathrm{P}$ fimbriae, respectively. Colonizations were performed with mixtures of the two transformants or all three strains.

IL-8 was detected in the urine of all patients after colonization with $E$. coli but not in precolonization samples. The lack of IL- 8 in serum samples taken during the colonization period suggested a mucosal production of this cytokine [122]. Levels of urinary IL-8 varied greatly from patient to patient, and showed no correlation with previously recorded urinary IL-6 levels or bacterial numbers $[101,135]$. In contrast, urinary IL-8 levels correlated strongly with neutrophil numbers (fig. 2). Peak urinary IL-8 levels corresponded with peak neutrophil numbers in all patients. Furthermore, patients with low levels of urinary IL- 8 had few neutrophils in their urine. The strong correlation with urinary neutrophil numbers suggested that IL-8 was involved in the induction of neutrophil influx and that neutrophils were a possible second source of this chemokine during UTI. Recent results 


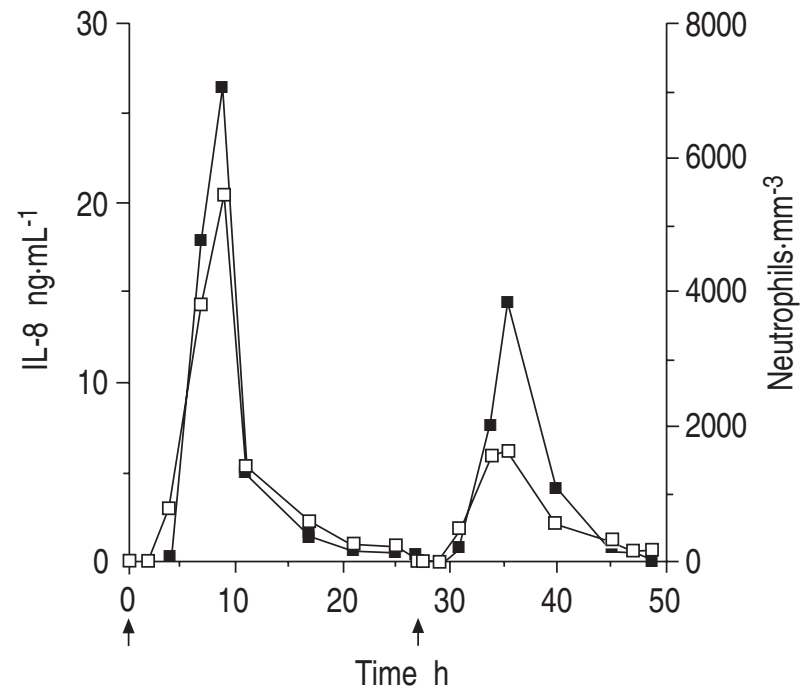

Fig. 2. - Correlation between urinary neutrophil numbers and urinary interleukin-8 (IL-8) levels after deliberate colonization of the human bladder with Escherichia coli. The arrows depict the times of colonization. $\longrightarrow$ : neutrophils; $\square-$ : IL-8.

have shown that all three colonization strains stimulate neutrophil IL-8 production in vitro (fig. 3). IL-8 production by neutrophils was not a result of LPS stimulation alone, since levels of IL-8 secreted in response to LPS were lower than to whole bacteria (fig. 4). Further preliminary data indicate that phagocytosis per se does not result in the high levels of IL-8 secretion observed after bacterial stimulation, since type 1 fimbriae coated fluorescein-labelled $0.75 \mu \mathrm{m}$ microspheres were phagocytosed by neutrophils and induced levels of IL-8 secretion similar to that of LPS (authors, unpublished observations).

a)

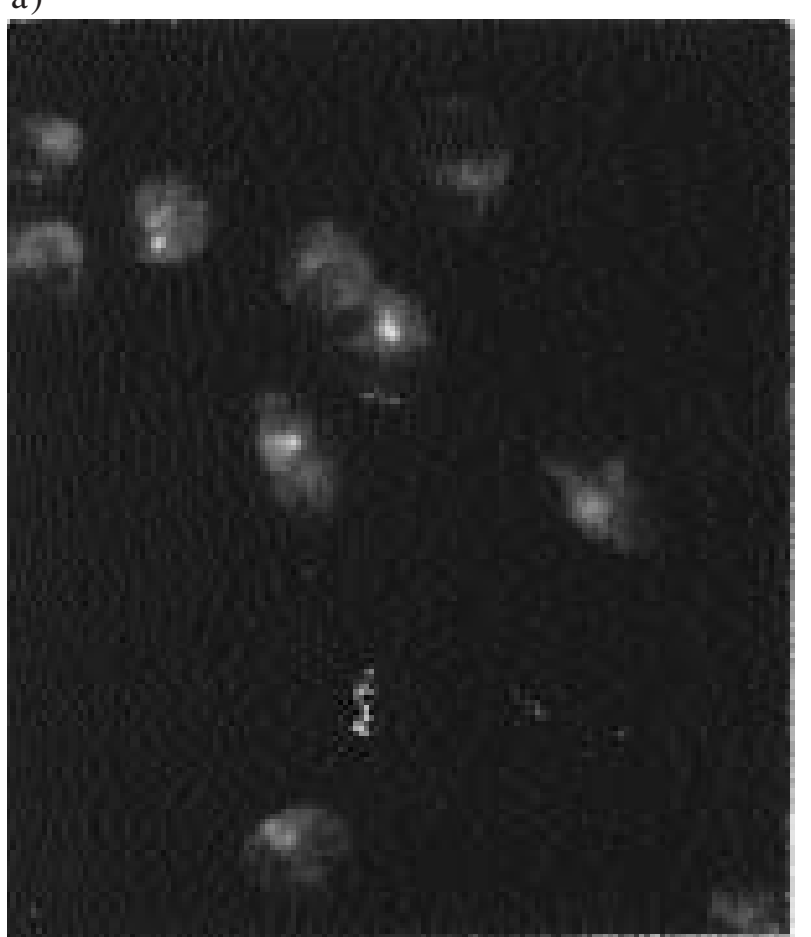

Together, these results show that IL-8 is produced at the urinary tract mucosa in response to $E$. coli infection and suggest that IL-8 is an important neutrophil chemoattractant during UTI. The cellular origin of mucosal IL-8 is not clear; however, since all three colonization strains stimulated urinary tract epithelial IL-8 production, it is likely that epithelial cells are involved in the initial IL-8 response to colonization [122]. The production of IL-8 by neutrophils in response to these strains suggests that these cells are a second source of urinary IL-8 once at the site of infection.

Since mixed inoculations of the bacterial strains were used to colonize patients, it was not possible to examine the role of bacterial adherence in the activation of the mucosal IL-8 response and neutrophil influx. However, a subsequent study has shown that monocolonization of the human urinary tract with the same ABU strain used in the above study [122], containing a single copy plasmid encoding the Pap $\mathrm{PA} 2_{2} \mathrm{P}$ fimbriae, induced significantly higher urinary IL-8 levels and neutrophil influx than monocolonization with the nonfimbriated parent strain (H. Connell, personal communication). Thus, bacterial adherence appears to influence epithelial IL-8 production in vitro and IL-8 secretion and neutrophil influx into the urinary tract in vivo.

IL-8 is also present at mucosal sites during natural infection. Urinary IL-8 levels are elevated in adults and children with UTI caused both by Gram-positive and Gram-negative bacteria [136-138]. High levels of IL-8 are found in the sputum of patients with cystic fibrosis that are chronically infected with $P$. aeruginosa, and IL- 8 producing cells are found in the intestinal epithelium during Shigella infection and in patients suffering H. pylori associated gastritis [139-141]. The local production of IL-8 is, therefore, a common occurrence during mucosal bacterial infection.

b)

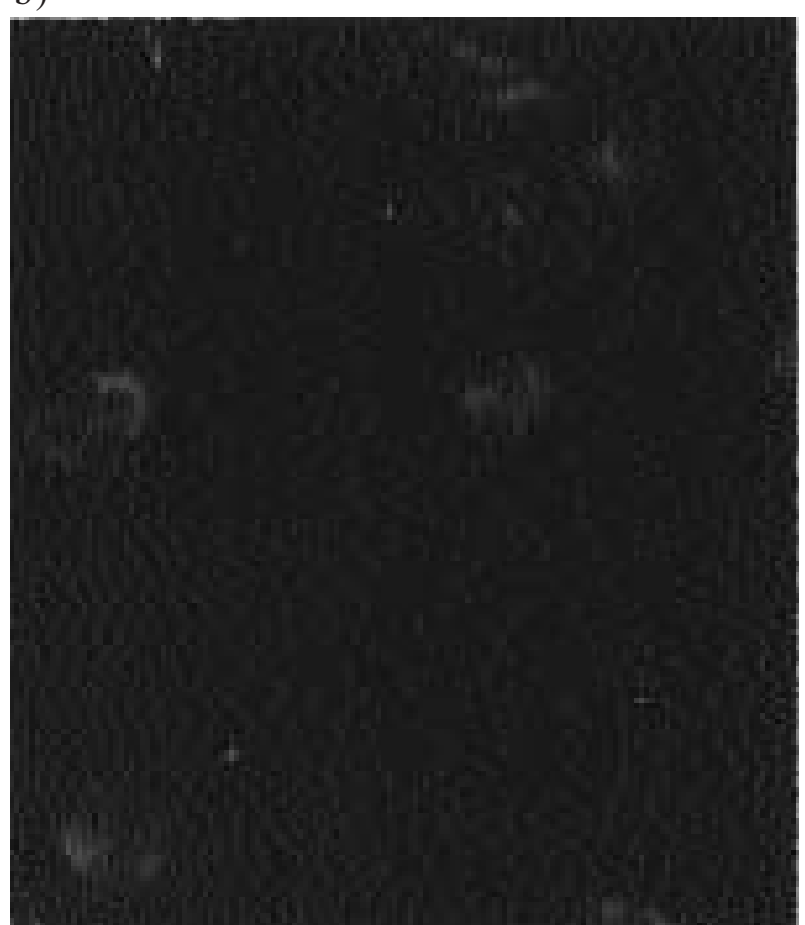

Fig. 3. - Interleukin-8 (IL-8) production by neutrophils in response to Escherichia coli. Staining was performed with anti-IL-8 antibody after stimulation with: a) E. coli; or b) medium alone. 
a)

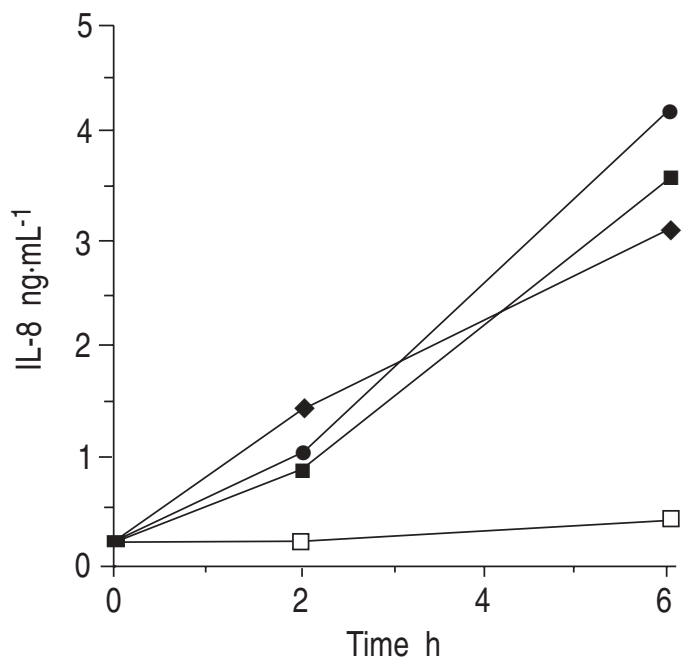

b)

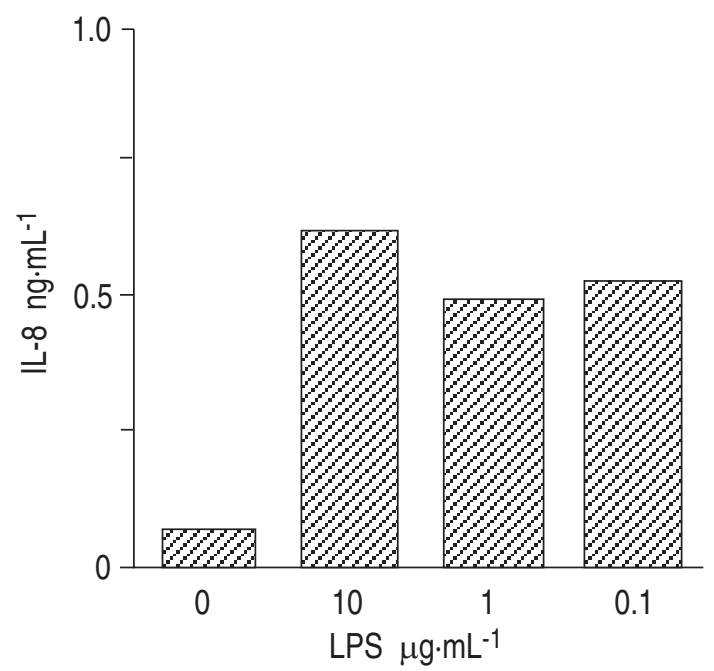

Fig. 4. - a) Secretion of interleukin-8 (IL-8) by neutrophils after stimulation with isogenic Escherichia coli strains (106 neutrophils.mL-1: $10^{8}$ bacteria. $\left.\mathrm{mL}^{-1}\right) . \longrightarrow-$ : control (medium alone); $\longrightarrow$ : nonfimbriated $E$. coli; $\longrightarrow$ : Type 1 fimbriated isogen; $\longrightarrow$ : $\mathrm{P}$ fimbriated isogen. b) IL-8 secretion by neutrophils $\left(10^{6} \cdot \mathrm{mL}^{-1}\right)$ after stimulation with LPS (E. coli serotype O:111) for 8 h. LPS: lipopolysaccharide.

\section{E. coli induced neutrophil migration across urinary tract epithelial layers}

Neutrophil migration to sites of infection or inflammation requires two events; 1 ) the production of a chemotactic signal originating from the inflammatory site; and 2) specific cellular interactions mediated through cell adhesion molecules expressed on the neutrophil surface and their ligands on the extracellular and cellular matrix. In order to examine whether E. coli induces neutrophil migration across epithelial cell layers and the role of IL-8 and cell adhesion molecules in this response, we developed an in vitro model based on the transwell system (fig. 5). Transwell inserts were placed into cluster dishes to form a two chamber system, separated by a polycarbonate membrane. The polycarbonate membrane contained $3 \mu \mathrm{m}$ pores, allowing the passage of cells from the top to the bottom chamber.

Kidney and bladder epithelial cell lines were grown to confluency on the underside of the membrane supports and prestimulated by addition of $E$. coli to the bottom well for 0,4 or $24 \mathrm{~h}$ [142]. After stimulation, medium in the top well was removed and replaced with new medium containing neutrophils. Neutrophil migration was measured by taking samples from the bottom well $3 \mathrm{~h}$ after

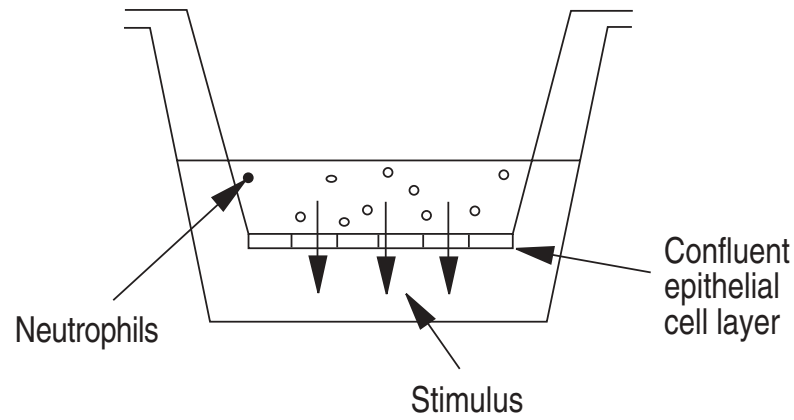

Fig. 5. - Transwell model used to study neutrophil migration across confluent urinary tract epithelial cell layers. their addition to the top well, and expressing the number of migrated neutrophils as a percentage of neutrophils added to the top well. In further experiments, epithelial layers were prestimulated for $24 \mathrm{~h}$ with IL-1 $\alpha$, LPS or preconditioned medium (obtained by incubating $E$. coli in cell medium in the presence of gentamycin for $24 \mathrm{~h}$ and removing the bacteria with a $0.22 \mu \mathrm{m}$ filter).

Preincubation of epithelial layers with E. coli for $24 \mathrm{~h}$ induced a marked increase in transuroepithelial neutrophil migration, which was stimulant dose- and timedependent [142]. E. coli failed to induce neutrophil migration when added to the epithelial layers at the same time as the neutrophils. Furthermore, E. coli were not themselves chemotactic for neutrophils in this model, since they failed to enhance neutrophil migration across filters in the absence of an epithelial layer. Together, these results indicate a requirement for epithelial cell activation in the induction of transuroepithelial neutrophil migration. E. coli LPS $\left(0.1-10 \mu \mathrm{g} \cdot \mathrm{mL}^{-1}\right)$ and pre-conditioned medium failed to induce transuroepithelial neutrophil migration, suggesting that whole bacteria were required for full induction of this response.

Table 2. - The role of IL-8 in Escherichia coli and IL$1 \alpha$ induced transuroepithelial neutrophil migration

\begin{tabular}{lccc}
\hline & \multicolumn{3}{c}{ Neutrophil migration $\%$} \\
\cline { 2 - 4 } Antibody $\quad 10 \mu \mathrm{g} \cdot \mathrm{mL}^{-1}$ & Medium & E. coli & $\mathrm{IL}-1 \alpha$ \\
\hline None & 23 & 71 & 82 \\
Monoclonal anti-IL-8 & 7 & 19 & 16 \\
Control & 23 & 62 & 68 \\
Washed cell layers & 18 & 63 & 76 \\
None & 12 & 15 & 15 \\
Monoclonal anti-IL-8 & 17 & 49 & 52 \\
Control & & & \\
\hline
\end{tabular}

Epithelial cell layers were prestimulated with $E$. coli $\left(10^{8} \mathrm{bac}-\right.$ teria. $\left.\mathrm{mL}^{-1}\right)$ or IL-1 $\alpha\left(1 \mathrm{ng} \cdot \mathrm{mL}^{-1}\right)$ for $24 \mathrm{~h}$. IL: interleukin; Control: monoclonal mouse immunoglobulin-G negative antibody. 


\section{Role of IL-8 in transuroepithelial neutrophil migration}

Since E. coli induced neutrophil migration across urinary tract epithelial cell layers required epithelial cell activation, we examined whether epithelial IL-8 production was involved in this process.

Anti-IL-8 antibody was added to $E$. coli and IL-1 $\alpha$ stimulated urinary tract epithelial layers $30 \mathrm{~min}$ prior to addition of the neutrophils. These antibodies completely blocked E. coli and IL-1 $\alpha$ induced transuroepithelial migration (table 2) [143]. Furthermore, IL-8 was sufficient to induce neutrophil migration across urinary tract epithelial layers, since addition of recombinant IL-8 to the lower well of unstimulated cell layers induced similar levels of migration as occurred across E. coli and IL- $1 \alpha$ stimulated cell layers. Several observations suggested that IL-8 was inducing transuroepithelial migration while bound to the epithelial surface and not as a soluble gradient. Firstly, neutrophil migration occurred across $E$. coli and IL-1 $\alpha$ stimulated epithelial cell layers that had been washed free of soluble IL- 8 , and this process was blocked with anti-IL-8 antibody (table 2). Secondly, staining of E. coli or IL- $1 \alpha$ stimulated epithelial layers with anti-IL- 8 antibody localized IL- 8 within the layers and at the epithelial surface (fig. 6). Thirdly, fluorescein-labelled IL-8 bound to the epithelial cells and binding was blocked with polyclonal anti-IL-8 antibody.

This study provided in vitro evidence that IL-8 can induce neutrophil migration across uroepithelial layers, and that uropathogenic $E$. coli induce migration, in part, by activating epithelial IL-8 production. IL- 8 appears to play a major role in E. coli and IL-1 $\alpha$ induced neutrophil migration, since antibodies to IL- 8 blocked all of the induced migration in response to these stimulants. These in vitro observations, are consistent with in vivo studies implicating IL-8 in the induction of neutrophil migration to sites of mucosal bacterial infection. IL- 8 levels

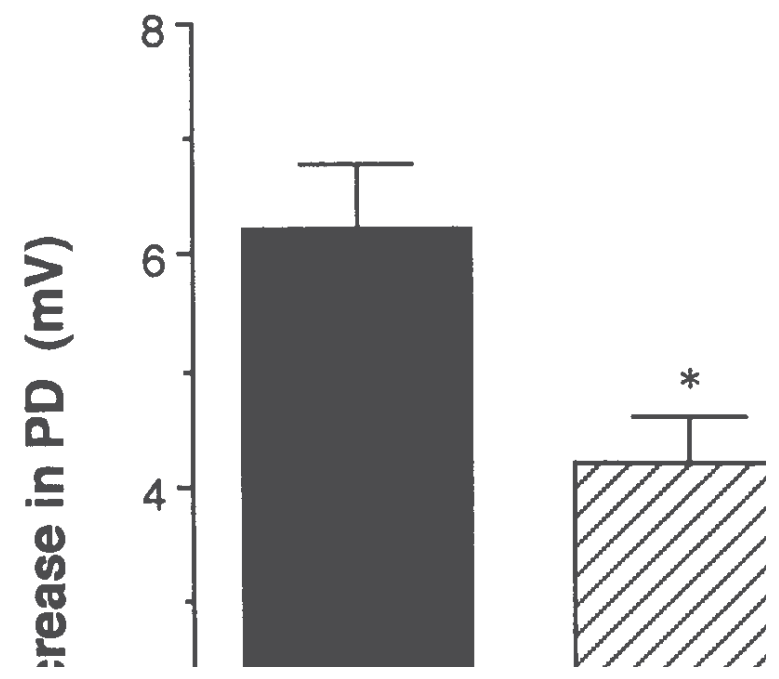

Fig. 6. - Stimulated urinary tract epithelial layers stained with antiinterleukin-8 (IL-8) antibody (green) and propidium iodide (red) and visualized with a confocal laser scanning microscope. The arrow depicts IL-8 at the epithelial surface. correlated strongly with neutrophil numbers in the urine of patients deliberately colonized in their bladders with E. coli and in patients with natural UTI [122, 136]. Anti-IL-8 antibody blocked, on average, $50 \%$ of the chemotactic activity of infected urine [136]. IL-8 levels were also shown to correlate with neutrophil numbers in bronchiolar lavage fluids from patients with $P$. aeruginosa infection, and IL-8 represented the majority of chemotactic activity in sputum samples obtained from patients with chronic airway disease [139, 144]. Taken together with the results of the present study, these observations suggest a role for mucosal IL-8 in establishing an early bound chemotactic gradient across the mucosal epithelium into the urine.

Both the bladder and kidney epithelial cell lines constitutively produced mRNA for IL-8RA and IL-8RB [143]. However, it seems unlikely that IL-8RA and IL-8RB are involved in presenting IL-8 to passing neutrophils as part of a haptotactic gradient, since binding of IL-8 to these receptors, at least in neutrophils, results in a rapid internalization of receptor bound IL-8 [91]. The expression and functional activity of these receptors on epithelial cells and the effects that IL- 8 has on urinary tract epithelial cells remains to be determined. Since proteoglycans have been proposed to present chemokines to neutrophils on endothelial cells (see above) [81], they are likely candidates in binding IL- 8 at epithelial surfaces and in building IL- 8 haptotactic gradients across urinary tract epithelial surfaces. The role of these molecules and possible additional IL-8 receptors in transuroepithelial neutrophil migration requires further study.

It remains to be seen whether epithelial cells from other mucosal sites are able to bind IL-8, and express mRNA for IL- 8 receptors. If this is the case, the results of the present study suggest IL- 8 may be playing an important role in directing neutrophil migration across the mucosal epithelium, not only in the urinary tract but also at other mucosal sites.

\section{Role of cell adhesion molecules in transuroepithelial neutrophil migration}

To examine the role of cell adhesion molecules in $E$. coli induced transuroepithelial neutrophil migration, we screened normal urinary tract epithelial cells and epithelial cell lines for the expression of ICAM-1, ICAM-2, E-selectin and P-selectin. We studied the ability of $E$. coli to upregulate cell adhesion molecule expression and blocked the function of these molecules in the transwell model with monoclonal antibodies.

Urinary tract epithelial cell lines and normal urinary tract epithelial cells constitutively expressed ICAM-1, but not E-selectin, P-selectin or ICAM-2 [142]. ICAM-1 expression on the urinary tract epithelial cells was augmented after stimulation with $E$. coli (fig. 7), with maximal levels being reached after 24-48 h of stimulation. Epithelial ICAM-1 expression was required for transuroepithelial cell migration in vitro, since anti-ICAM-1 antibody and anti-ICAM-1 Fab fragments blocked E. coli and IL- $1 \alpha$ induced transuroepithelial neutrophil migration (table 3). In contrast, anti-human leucocyte antigen1 (HLA-1) antibody, which bound to the epithelial cells to a similar degree as the anti ICAM-1 antibody, had no 
a)

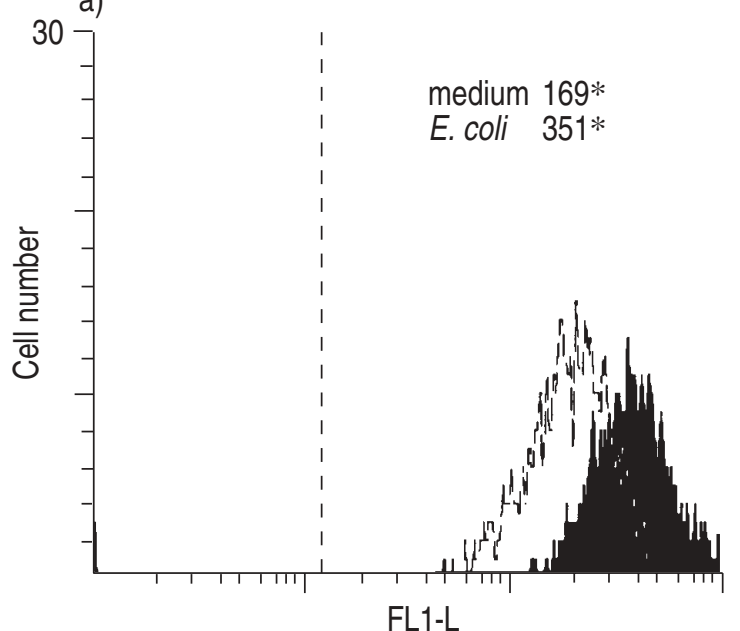

b)

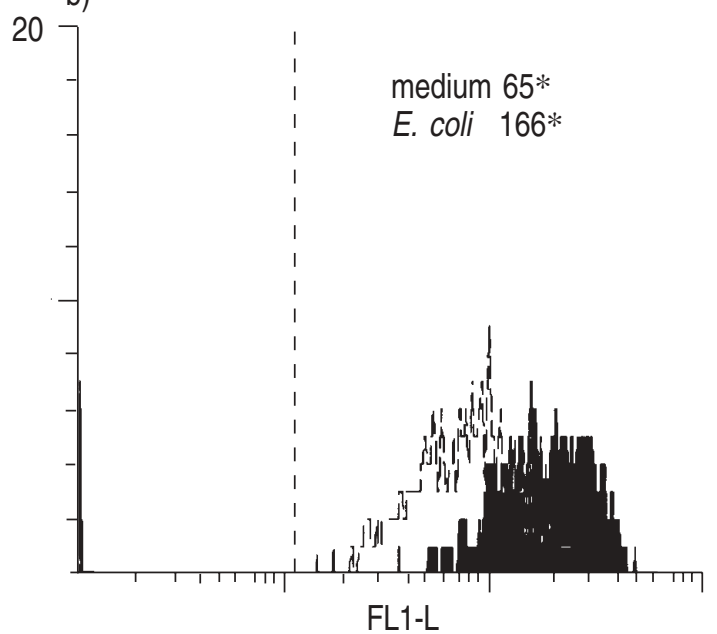

Fig. 7. - Flow cytometry analysis of ICAM-1 expression on urinary tract epithelial cells after stimulation with medium or Escherichia coli for $24 \mathrm{~h}$. a) A-498 kidney epithelial cells; b) J82 bladder epithelial cells. (Of cells incubated with the monoclonal mouse immunoglobulin-G negative antibody, $98 \%$ fell to the left of the dotted line (data not shown)). $\square$ : medium; $\square$ : coli. ICAM-1: intercellular adhesion molecule1; FL1-L: Log fluorescence intensity; *: mean fluorescence.

effect on transuroepithelial neutrophil migration. The neutrophil ligand for ICAM-1 was tentatively identified as Mac-1, since anti-CD11b and anti-CD18 but not antiCD11a antibody also blocked migration (table 3 ).

Previous studies have shown that mucosal epithelial cells express ICAM-1. Epithelial cells from the lung, and the intestine constitutively express ICAM-1, and expression is augmented by proinflammatory cytokines [145147]. The expression of ICAM-1 by human bronchial epithelium in vitro correlates with increased binding of activated neutrophils to monolayers of bronchial epithelial cells. This attachment can be inhibited with antiICAM-1 antibody [145]. ICAM- 1 is also expressed by urinary tract epithelial cells. ICAM-1 is constitutively expressed by primary tubular epithelial cells in culture, and expression is augmented by proinflammatory cytokines [148]. In addition cytokine stimulated primary urothelial epithelial cells, proliferating ureter epithelial cells, and numerous bladder epithelial cell lines express ICAM-1 [149-151]. Weak ICAM-1 expression is observed in normal kidney epithelium in vivo and is upregulated during renal disease [152-154]. ICAM-1 is also expressed on bladder urothelial cells in patients with interstitial

Table 3. - The role of cell adhesion molecules in Escherichia coli induced transepithelial neutrophil migration

\begin{tabular}{lccc}
\hline & \multicolumn{3}{c}{ Neutrophil migration $\%$} \\
\cline { 2 - 4 } Antibody $\quad\left(10 \mu \mathrm{g} \cdot \mathrm{mL}^{-1}\right)$ & Medium & E. coli & $\mathrm{IL}-1 \alpha$ \\
\hline None & 8 & 53 & 52 \\
Anti-ICAM-1 & 2 & 8 & 15 \\
Control & 11 & 45 & 48 \\
None & 27 & 79 & 63 \\
Anti-CD11a & 27 & 73 & 53 \\
Anti-CD11b & 9 & 23 & 16 \\
Anti-CD18 & 3 & 21 & 13 \\
\hline
\end{tabular}

Epithelial cells layers were prestimulated with E. coli $\left(10^{8} \mathrm{bac}-\right.$ teria $\left.\cdot \mathrm{mL}^{-1}\right)$ or interleukin-1 $\alpha(\mathrm{IL}-1 \alpha)\left(1 \mathrm{ng} \cdot \mathrm{mL}^{-1}\right)$. ICAM-1: intercellular adhesion molecule-1; Control: monoclonal mouse immunoglobulin negative antibody. cystitis [151], and on normal bladder urothelium in patients after instillation of Calmette-Guérin bacillus (BCG) [155].

Preliminary results from our group examining ICAM-1 expression in vivo indicate constitutive expression of ICAM-1 in the glomeruli, endothelial vessels, and the basolateral side of kidney tubular epithelium in the mouse (authors unpublished observation) and strong ICAM-1 staining in the kidney glomeruli and weak ICAM-1 staining throughout the kidney tubular and bladder epithelium in the human (H. Long, unpublished observation). Whilst the results presented here show that E. coli can upregulate the expression of cell adhesion molecules on the surface of urinary tract epithelial cells and that these cell adhesion molecules are required for neutrophil migration across urinary tract epithelial layers in vitro, the kinetics of ICAM-1 expression by kidney and bladder epithelium and its role in neutrophil migration in vivo during bacterial infection are yet to be determined.

\section{Concluding remarks}

It is now becoming clear that mucosal inflammation and, particularly, neutrophil influx plays a key role in the clearance of bacteria from the urinary tract at the onset of infection. $\mathrm{C} 3 \mathrm{H} / \mathrm{HeJ}$ mice that are hyporesponsive to LPS, have significantly higher bacterial numbers in their bladders and kidneys $24 \mathrm{~h}$ after intravesical infection with $E$. coli, compared to normal $\mathrm{C} 3 \mathrm{H} / \mathrm{HeN}$ mice [156]. This corresponds with a significantly lower inflammatory response (neutrophil influx and urinary IL-6 levels) in $\mathrm{C} 3 \mathrm{H} / \mathrm{HeJ}$ mice $[100,157]$. Macrophages from $\mathrm{C} 3 \mathrm{H} / \mathrm{HeJ}$ mice were recently shown to be nonresponsive to the lipid second messenger ceramide, that has been implicated in TNF- $\alpha$, IL-1 $\beta$, interferon- $\gamma$ (IFN- $\gamma$ ) and more recently $\mathrm{P}$ fimbriated $E$. coli signalling pathways $[125,158]$. The inability of $\mathrm{C} 3 \mathrm{H} / \mathrm{HeJ}$ mice to mount an inflammatory response to $E$. coli infection may, therefore, be due to an insensitivity to numerous alternative inducers of this pathway other than LPS. C57BL/10ScCr 
LPS hyporesponder mice also have significantly higher bacterial numbers in their bladders and kidneys after 24 $\mathrm{h}$ infection compared to normal C57BL/6J mice [159]. In both $\mathrm{C} 3 \mathrm{H}$ and $\mathrm{C} 57$ mouse backgrounds the presence of neutrophils in the urine corresponds with clearance of infection. Furthermore, treatment of $\mathrm{C} 3 \mathrm{H} / \mathrm{HeN}$ mice with the anti-inflammatory drugs, dexamethasone, diclofenac and indomethacin, severely inhibited their ability to clear infection [160]. A role of neutrophil influx in the clearance of UTI has also been reported by MiLLER et al. [161], who showed that treatment of rats with antineutrophil serum led to a 1,000 fold increase in bacterial numbers in infected kidneys [161]. These results suggest that the inflammatory response, particularly neutrophil influx to infection, is important in the clearance of infection.

The work presented in this review has highlighted the importance of epithelial cells and bacterial/epithelial interactions in the induction of neutrophil influx during mucosal infection and has shown the necessity for hostderived chemotactic factors and cell adhesion molecules for neutrophil influx across epithelial layers in vitro. Based on this data, we propose the following model of E. coli induced neutrophil migration during UTI. E. coli first induce the secretion of cytokines, including IL-8, and the upregulation of adhesion molecules at the mucosal epithelial lining. The degree of IL-8 production will be influenced by the adherence and presumably other virulence properties of the bacteria. A chemotactic gradient is formed and neutrophils migrate from the vasculature to the subepithelial tissue. This gradient is likely

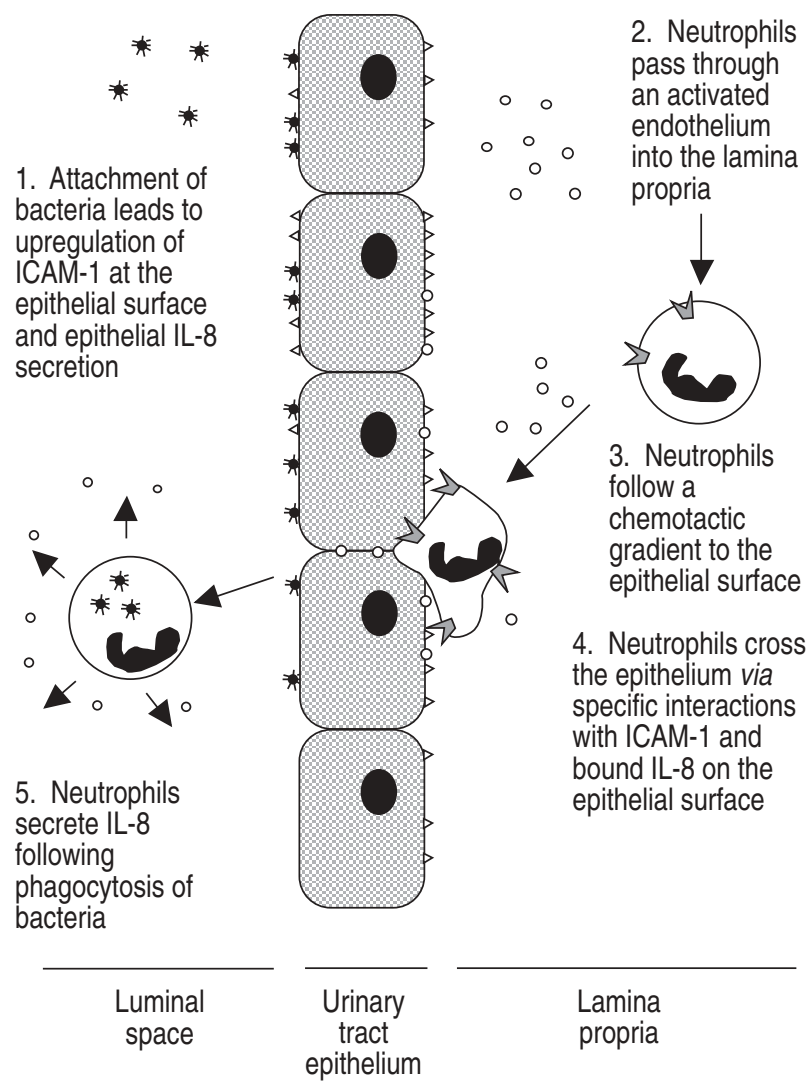

Fig. 8. - Schematic model Escherichia coli induced neutrophil migration across urinary tract epithelium. $\bigcirc$ : interleukin-8 (IL-8); $\triangleright$ : intercellular adhesion molecule-1 (ICAM-1); $\nabla:$ Mac-1; * : E. coli. ICAM-1: intercellular adhesion molecule-1; IL-8: interleukin-8. to involve IL-8, since staining of human bladder mucosa has shown IL-8 to be present within the mucosal tissue during inflammation (H. Long, personal communication). Finally mucosal IL-8 bound to the urinary tract epithelial cell surface induces neutrophil migration across the epithelium into the luminal space. Neutrophil Mac-1 and epithelial ICAM-1 expression are also necessary for migration across the urinary tract epithelium in vitro. Strong IL-8 staining is observed in the inflamed human urinary tract epithelium (H. Long, personal communication). Once at the site of infection, neutrophils may secrete IL-8 and, therefore, help to regulate the migration process (fig. 8).

Further work examining the importance of the $\alpha$ chemokines and cell adhesion molecules in E. coli induced neutrophil influx to the urinary tract in vivo is underway, using antibodies to specifically block the function of these molecules. Results obtained from these studies should help us obtain a clearer understanding of the mechanisms of neutrophil migration to the urinary tract mucosa and their role in the different stages of the disease process.

\section{References}

1. Muller W, Weigl S, Deng X, Phillips D. PECAM-1 is required for transendothelial migration of leukocytes. J Exp Med 1993; 178: 449-460.

2. Newman P, Berndt M, Gorski J, et al. PECAM-1 (CD31) cloning and relation to adhesion molecules of the immunoglobulin superfamily. Science 1990; 247: 1219-1222.

3. Muller W, Ratti C, McDonnell S, Cohn Z. A human endothelial cell-restricted, externally disposed plasmalemmal protein enriched in intercellular junctions. $J$ Exp Med 1989; 170: 399-414.

4. Stockinger H, Gadd S, Ether R, et al. Molecular characterisation and functional analysis of the leukocyte surface protein CD31. J Immunol 1990; 145: 3889-3897.

5. Lawrence M, Springer T. Leukocytes roll on a selectin at physiologic flow rates: distinction from and prerequisite for adhesion through integrins. Cell 1991; 65: 859-873.

6. Lawrence M, Springer T. Neutrophils roll on E-selectin. J Immunol 1993; 151: 6338-6346.

7. Ley K, Bullard D, Arbonés M, et al. Sequential rolling of L- and P-selectin to leukocyte rolling in vivo. J Exp Med 1995; 181: 669-675.

8. Nelson R, Dolich S, Aruffo A, Cecconi O, Bevilacqua M. High affinity oligosaccharide ligands for E-selectin. J Clin Invest 1993; 91: 1157-1166.

9. Bevilacqua M, Nelson R. Selectins. J Clin Invest 1993; 91: 379-387.

10. McEver R, Beckstead J, Moore K, Marshall Carlson L, Bainton D. GMP-140, a platelet alpha granule membrane protein, is also synthesized by vascular endothelial cells and is localised in Weibel-Palade bodies. $J$ Clin Invest 1989; 84: 92-99.

11. Hattori R, Hamilton K, Fugate R, McEver R, Sims P. Stimulated secretion of endothelial vonWillebrand factor is accompanied by rapid redistribution to the cell surface of the intracellular granule membrane protein GMP-140. J Biol Chem 1989; 264: 7768.

12. Bonfanti R, Furie B, Furie B, Wagner D. PADGEM (GMP-140) is a component of Weibel-Palade bodies of human endothelial cells. Blood 1989; 73: 1109-1112.

13. Geng J, Bevilacqua M, Moore K, et al. Rapid neutrophil 
adhesion to activated endothelium mediated by GMP-140. Nature 1990; 343: 757-760.

14. Lorant $\mathrm{D}$, Topham $\mathrm{M}$, Whatley $\mathrm{R}$, et al. In-flammatory roles of P-selectin. J Clin Invest 1993; 92: 559-570.

15. Bullard D, Qin L, Lorenzo I, et al. P-selectin/ICAM-1 double mutant mice: acute emigration of neutrophils into the peritoneum is completely absent but is normal into pulmonary alveoli. J Clin Invest 1995; 95: 1782-1788.

16. Bevilacqua M, Stengelin S, Gimbrone M, Seed B. Endothelial leukocyte adhesion molecule 1: an inducible receptor for neutrophils related to complement regulatory proteins and lectins. Science 1989; 243: 1160-1164.

17. Pober J, Gimbrone M, Lapierre L, Mendrick D, Rothlein $\mathrm{R}$, Springer T. Overlapping patterns of activation of human endothelial cell by interleukin-1, tumor necrosis factor, and immune interferon. J Immunol 1986; 137: 1893-1896.

18. Lo S, Lee S, Ramos R, et al. Endothelial leucocyte adhesion molecule-1 stimulates the adhesive activity of CR3 (CD11b/CD18, Mac-1, $\alpha \mathrm{m} \beta 2$ ) on human neutrophils. J Exp Med 1991; 173: 1493-1500.

19. Gundel R, Wegner C, Torcellini C, et al. Endothelial-leucocyte adhesion molecule-1 mediates antigen-induced acute airway inflammation and late phase airway obstruction in monkeys. J Clin Invest 1991; 88: 1407-1411.

20. Mulligan M, Varani S, Dame M, et al. Role of endothelial-leucocyte adhesion molecule 1 (ELAM-1) in neutrophil-mediated lung injury in rats. J Clin Invest 1991; 88: $1396-1406$.

21. Spertini O, Luscinskas FW, Kansas GS, et al. Leukocyte adhesion molecule-1 (LAM-1, L-selectin) interacts with an inducible endothelial cell ligand to support leukocyte adhesion. J Immunol 1991; 147: 2565-2573.

22. Kishimoto T, Jutila M, Berg E, Butcher E. Neutrophil Mac-1 and MEL-14 adhesion proteins inversely regulated by chemotactic factors. Science 1989; 245: 1238-1241.

23. Spertini O, Kansas G, Munro J, Griffin J, Tedder T. Regulation of leucocyte migration by activation of the leucocyte adhesion molecule-1 (LAM-1) selectin. Nature 1991; 349: 691-693.

24. Crockett-Torabi E, Sulenbarger B, Wayne Smith C, Fantone J. Activation of human neutrophils through L-selectin and Mac-1 molecules. J Immunol 1995; 154: 2291-2302.

25. Mulligan M, Miyasaka M, Tamatani T, Jones M, Ward P. Requirements for L-selectin in neutrophil-mediated lung injury. J Immunol 1992; 152: 832-840.

26. Watson S, Fennie C, Lasky L. Neurophil influx into an inflammatory site inhibited by a soluble homing receptor-IgG chimera. Nature 1991; 349: 164-167.

27. Wayne Smith C, Marlin S, Rothlein R, Toman C, Anderson D. Co-operative interactions of LFA-1 and Mac-1 with intercellular adhesion molecule-1 in facilitating adherence and transendothelial migration of human neutrophils in vitro. J Clin Invest 1989; 83: 2008-2017.

28. Zimmerman G, McIntyre T. Neutrophil adherence to human endothelium occurs by CDw18 (Mol, MAC-1/ LFA-1/GP-150,95) glycoprotein-dependent and independent mechanisms. J Clin Invest 1988; 81: 531-537.

29. Stacker S, Springer T. Leucocyte integrin p159,95 (CD11c/CD18) functions as an adhesion molecule binding to counterreceptor on stimulated endothelium. $J$ Immunol 1991; 146: 648-655.

30. Bainton D, Miller L, Kishimoto T, Springer T. Leucocyte adhesion receptors are stored in peroxidase negative granules of human neutrophils. J Exp Med 1987; 166: $1641-1653$.
31. Todd III R, Arnout M, Rosin R, et al. Subcellular localization of Mol (Mol alpha; formerly gp110), a surface glycoprotein associated with neutrophil adhesion. J Clin Invest 1984; 74: 1280-1290.

32. Miller L, Bainton D, Borregaard N, Springer T. Stimulated mobilization of monocyte Mac-1 and p150,95 adhesion proteins from an intracellular vesicular compartment to the cell surface. J Clin Invest 1987; 1987: 535-544.

33. Segeløv H, Kjeldsen L, Diamond M, Springer T, Borregaard N. Subcellular localization and dynamics of Mac-1 ( $\alpha \mathrm{M} \beta 2)$ in human neutrophils. J Clin Invest 1993; 92: $1467-1476$

34. Vedder N, Harlan J. Increased surface expression of $\mathrm{CD} 11 \mathrm{~b} / \mathrm{CD} 18$ (Mac-1) is not required for stimulated neutrophil adherence to cultured endothelium. J Clin Invest 1988; 81: 676-682.

35. Hughes B, Hollers J, Crockett-Torabi E, Wayne Smith C. Recruitment of CD11b/CD18 to the neutrophil surface and adherence-dependent cell locomotion. J Clin Invest 1992; 90: 1687-1696.

36. Hibbs M, Jakes S, Stacker S, Wallace R, Springer T. The cytoplasmic domain of the integrin lymphocyte function-associated antigen $1 \beta$ subunit: sites required for binding to intercellular adhesion molecule- 1 and the phorbal ester-stimulated phosphorylation site. J Exp Med 1991; 174: 1227-1238.

37. Hibbs M, Xu H, Stacker S, Springer T. Regulation of adhesion to ICAM-1 by the cytoplasmic domain of LFA-1 integrin beta subunit. Science 1991; 251: 1611-1613.

38. Kuijpers T, Mul E, Blom M, Kovach N, et al. Freezing adhesion molecules in a state of high avidity binding blocks eosinophil migration. J Exp Med 1993; 178: 279-284.

39. Doerschuk C, Winn R, Coxson H, Harlan J. CD18-dependent and independent mechanisms of neutrophil emigration in the pulmonary and systemic microcirculation of rabbits. J Immunol 1990; 144: 2327-2333.

40. Conlan W, North R. Listeria monocytogenes, but not Salmonella typhimurium, elicits a CD18-independent mechanism of neutrophil extravasation into the murine peritoneal cavity. Infect Immun 1994; 62: 2702-2706.

41. Fougerolles A, Stacker S, Schwarting R, Springer T. Characterization of ICAM-2 and evidence for a third counterreceptor for LFA-1. J Exp Med 1991; 174: 253-267.

42. Diamond M, Staunton D, de Fougerolles A, et al. ICAM-1 (CD54), a counterreceptor for Mac-1 (CD11b/CD18). J Cell Biol 1990; 111: 3129-3139.

43. Staunton D, Dustin M, Erickson H, Springer T. The arrangement of the immunoglobulin-like domains of ICAM-1 and the binding sites for LFA-1 and rhinovirus. Cell 1990; 61: 243-245.

44. Xie J, Li R, Kotovuori P, Vermot-Desroches C, et al. Intercellular adhesion molecule-2 (CD102) binds to the leukocyte integrin CD11b/CD18 through the A domain. J Immunol 1995; 155: 3619-3628.

45. Staunton D, Dustin M, Springer T. Fuctional cloning of ICAM-2, a cell adhesion ligand for LFA-1 homologous to ICAM-1. Nature 1989; 339: 61-64.

46. Nortamo P, Rui L, Renkonen R, et al. The expression of intercellular adhesion molecule-2 is refractory to inflammatory cytokines. Eur J Immunol 1991; 21: 26292632.

47. Mulligan M, Wilson G, Todd R, et al. Role of $\beta 1, \beta 2$ integrins and ICAM-1 in lung injury after deposition of IgG and IgA immune complexes. J Immunol 1993; 150: 2407-2417.

48. Mulligan M, Wayne Smith C, et al. Role of leucocyte 
adhesion molecules in complement-induced lung injury. J Immunol 1993; 150: 2401-2406.

49. Horgan M, Ge M, Gu J, Rothlein R, Malik A. Role of ICAM-1 in neutrophil-mediated lung vascular injury after occlusion and reperfusion. Am J Physiol 1991; 261: H1578.

50. Sligh J, Ballantyne C, Rich S, et al. Inflammatory and immune responses are impaired in mice deficient in intercellular adhesion molecule-1. Proc Natl Acad Sci 1993; 90: 8529-8533.

51. $\mathrm{Xu} \mathrm{H}$, Gonzales J, St. Pierre Y, et al. Leukocytosis and resistance to septic shock in intercellular adhesion molecule-1 deficient mice. J Exp Med 1994; 180: 95-109.

52. Baggiolini M, Dewald B, Moser B. Interleukin-8 and related chemotactic cytokines-CXC and CC chemokines. Adv Immunol 1994; 55: 97-179.

53. Clark-Lewis I, Dewald B, Geiser T, Moser B, Baggiolini M. Platelet factor- 4 binds to interleukin- 8 receptors and activates neutrophils when its $\mathrm{N}$ terminus is modified with Glu-Leu-Arg. Proc Natl Acad Sci 1993; 90: 3574-3577.

54. Yoshimura T, Robinson E, Appella E, et al. Three forms of monocyte-derived neutrophil chemotactic factor (MDNCF) distinguished by different lengths of the amino terminal sequence. Mol Immunol 1989; 26: 87-93.

55. Van Damme J, Van Beeumen J, Conings R, Decock B, Billiau A. Purification of granulocyte chemotactic peptide/interleukin-8 reveals N-terminal sequence heterogeneity similar to that of beta-thromboglobulin. Eur $J$ Biochem 1989; 181: 337-344.

56. Lindley I, Aschauer H, Seifert J, et al. Synthesis and expression in Escherichia coli of the gene encoding monocyte-derived neutrophil-activating factor: biological equivalence between natural and recombinant neutrophil-activating factor. Proc Natl Acad Sci 1988; 85: 9199-9203.

57. Gimbrone MJ, Obin MS, Brock AF, et al. Endothelial interleukin-8: a novel inhibitor of leukocyte-endothelial interactions. Science 1989; 246: 1601-1603.

58. Nakagawa H, Hatakeyama S, Ikesue A, Miyai H. Generation of interleukin-8 by plasmin from AVLPR-interleukin-8, the human fibroblast-derived neutrophil chemotactic factor. FEBS Lett 1991; 282: 412-414.

59. Hébert C, Luscinskas F, Kiely J, et al. Endothelial and leukocyte forms of IL-8: conversion of thrombin and interactions with neutrophils. J Immunol 1990; 145: 3033-3040.

60. Nourshargh S, Perkins J, Showell H, Matsushima K, Williams T, Collins P. A comparative study of the neutrophil stimulatory activity in vitro and proinflammatory properties in vivo of 72 amino acid and 77 amino acid IL-8. J Immunol 1992; 148: 106-111.

61. Baldwin E, Weber I, St. Charles R, et al. Crystal structure of interleukin-8: symbiosis of NMR and crystallography. Proc Natl Acad Sci 1991; 88: 502-506.

62. Clore G, Appella E, Yamada M, Matsushima K, Gronenborn A. Three-dimensional structure of interleukin 8 in solution. Biochem J 1990; 29: 1689-1696.

63. Rajarathnam K, Sykes B, Kay C, et al. Neutrophil activation by monomeric interleukin-8. Science 1994; 254: 90-92.

64. Paolini J, Willard D, Consler T, Luther M, Krangel M. The chemokines, IL-8, monocyte chemoattractant protein-1, and I-309 are monomers at physiologically relevant concentrations. J Immunol 1994; 153: 2704-2717.

65. Yoshimura T, Matsushima K, Oppenheim J, Leanard E. Neutrophil chemotactic factor produced by lipopolysaccharide (LPS)-stimulated human blood mononuclear leukoctes: partial characterisation and separation from interleukin-1 (IL-1). J Immunol 1987; 139: 788-793.

66. Peveri P, Walz A, Dewald B, Baggiolini M. A novel neutrophil-activating factor produced by human mononuclear phagocytes. J Exp Med 1988; 167: 1547-1559.

67. Brandt E, Peterson F, Flad H. Recombinant tumor necrosis factor- $\alpha$ potentiates neutrophil degranulation in response to host defense cytokines neutrophil-activating peptide 2 and IL- 8 by modulating intracellular cyclic AMP levels. J Immunol 1992; 149: 1356-1364.

68. Walz A, Meloni F, Clark LI, von TV, Baggiolini M. $\left(\mathrm{Ca}^{2+}\right) \mathrm{i}$ changes and respiratory burst in human neutrophils and monocytes induced by NAP-1/interleukin-8, NAP-2, and gro/MGSA. J Leukoc Biol 1991; 50: 279-286.

69. Willems J, Joniau M, Cinque S, van Damme J. Human granulocyte chemotactic peptide (IL-8) as a specific neutrophil degranulator: comparison with other monokines. Immunology 1989; 67: 540-542.

70. Detmers PA, Lo SK, Olsen EE, Walz A, Baggiolini M, Cohn ZA. Neutrophil-activating protein-1/interleukin-8 stimulates the binding activity of the leukocyte adhesion receptor CD11b/CD18 on human neutrophils. J Exp Med 1990; 171: 1155-1162.

71. Loike J, El Khoury J, Cao L, et al. Fibrin regulates neutrophil migration in response to interleukin-8, leukotriene $\mathrm{B}_{4}$, tumour necrosis factor, and formyl-methionyl-leucylphenylalanine. J Exp Med 1995; 181: 1763-1772.

72. Huber A, Kunkel S, Todd R, Weiss S. Regulation of transendothelial neutrophil migration by endogenous interleukin-8. Science 1991; 254: 99-102.

73. Colditz I, Zwahlen R, Dewald B, Baggiolini M. In vivo inflammatory activity of neutrophil-activating factor, a novel chemotactic peptide from human monocytes. Am J Pathol 1989; 134: 755-760.

74. Colditz IG, Zwahlen RD, Baggiolini M. Neutrophil accumulation and plasma leakage induced in vivo by neutrophil-activating peptide-1. J Leukoc Biol 1990; 48: 129-137.

75. Hechtman D, Cybulsky M, Fuchs H, Baker J, Gimbrone M. Intravascular IL-8: inhibitor of polymorphonuclear leukocte accumulation at sites of acute inflammation. $J$ Immunol 1991; 147: 883-892.

76. Simonet W, Hughes T, Nguyen H, Trebasky L, Danilenko $\mathrm{D}$, Medlock E. Long-term impaired neutrophil migration in mice overexpressing human interleukin-8. J Clin Invest 1994; 94: 1310-1319.

77. Moser R, Olgiati L, Patarroyo M, Fehr J. Chemotaxins inhibit neutrophil adherence to and transmigration across cytokine-activated endothelium: correlation to the expression of L-selectin. Eur J Immunol 1992; 23: 1481-1487.

78. Ley K, Baker J, Cybulsky M, Gimbrone M, Luscinskas F. Intravenous interleukin-8 inhibits granulocyte migration from rabbit mesenteric venules without altering Lselectin expression or leukocyte rolling. J Immunol 1993; 151: 6347-6357.

79. Westlin W, Kiely J, Gimbrone M. Interleukin-8 induces changes in human neutrophil actin conformation and distribution: relationship to inhibition of adhesion to cytokineactivated endothelium. J Leukocyte Biol 1992; 52: 43-51.

80. Rot A. Endothelial cell binding of NAP-1/IL-8: role in neutrophil emigration. Immunol Today 1992; 13: 291-294.

81. Tanaka Y, Adams D, Shaw S. Proteoglycans on endothelial cells present adhesion-inducing cytokines to leukocytes. Immunol Today 1993; 14: 111-115.

82. Schulz B, Michel G, Wagner S, et al. Increased expression of epidermal IL-8 receptor in psoriasis. J Immunol 1993; 151: 4399-4406. 
83. Rot A. Binding of neutrophil attractant/activation protein-1 (interleukin-8) to resident dermal cells. Cytokine 1992; 4: 347.

84. Schönbeck U, Brandt E, Peterson F, Flad H, Loppnow H. IL-8 specifically binds to endothelial but not to smooth muscle cells. J Immunol 1995; 154: 2375-2383.

85. Samanta A, Oppenheim J, Matsushima K. Identification and characterization of specific receptors for monocytederived neutrophil chemotactic factor (MDNCF) on human neutrophils. J Exp Med 1989; 169: 1185-1189.

86. Holmes W, Lee J, Kuang W, Rice G, Wood W. Structure and functional expression of a human interleukin-8 receptor. Science 1991; 253: 1278-1280.

87. Murphy P, Tiffany H. Cloning of complementary DNA encoding a functional human interleukin-8 receptor. Science 1991; 253: 1280-1283.

88. Lee J, Horuk R, Rice R, Bennett G, Camerato T, Wood W. Characterization of two high affinity human interleukin-8 receptors. J Biol Chem 1992; 267: 16283-16287.

89. LaRosa G, Thomas K, Kaufman M, et al. Amino terminus of the interleukin- 8 receptor is a major determinant of receptor subtype specificity. J Biol Chem 1992; 267: 25402-25406.

90. Moser B, Barella L, Mattei S, et al. Expression of transcripts for two interleukin-8 receptors in human phagocytes, lymphocytes and melanoma cells. Biochem J 1993; 294: 285-292.

91. Chuntharapai A, Jin Kim K. Regulation of the expression of IL-8 receptor A/B by IL-8: possible functions of each receptor. J Immunol 1995; 155: 2587-2594.

92. Hammond $\mathrm{M}$, Lapointe $\mathrm{G}$, Feucht $\mathrm{P}$, et al. IL-8 induces neutrophil chemotaxis predominantly via type 1 IL-8 receptors. J Immunol 1995; 155: 1428-1433.

93. Horuk R, Chitnis C, Darbonne W, et al. A receptor for the malarial parasite Plasmodium vivax: the erythrocyte chemokine receptor. Science 1993; 261: 1182-1184.

94. Hadley T, Lu Z, Wasniowska K, et al. Postcapillary venule endothelial cells in kidney express a multispecific chemokine receptor that is structurally and functionally identical to the erythroid isoform, which is the duffy group antigen. J Clin Invest 1994; 94: 985-991.

95. Darbonne W, Rice G, Mohler M, et al. Red blood cells are a sink for interleukin-8, a leukocyte chemotaxin. $J$ Clin Invest 1991; 88: 1362-1369.

96. Webb L, Ehrengruber M, Clark-Lewis I, Baggiolini M, Rot A. Binding to heparan sulphate or heparin enhances neutrophil responses to IL-8. Proc Natl Acad Sci 1993; 90: 7158-7162.

97. Bettelheim K, Taylor J. A study of Escherichia coli isolated from chronic urinary tract infection. J Med Microbiol 1969; 2: 225-236.

98. Lidin-Janson G, Hanson L, Kaijser B. Comparison of Escherichia coli from bacteriuric patients with those from feces of healthy school children. J Infect Dis 1977; 136: 346-353.

99. Plos K, Connell H, Jodal U, et al. Intestinal carriage of P fimbriated Escherichia coli and the susceptibility to urinary tract infection in young children. $J$ infect Dis 1995; 171: 625-631.

100. Shahin R, Engberg I, Hagberg L, Svanborg-Edén C. Neutrophil recruitment and bacterial clearance correlated with LPS responsiveness in local Gram-negative infection. J Immunol 1987; 138: 3475-3480.

101. Hedges S, Anderson P, Lidin-Janson G, de Man P, Svanborg C. Interleukin-6 response to deliberate colonization of the human urinary tract with Gram-negative bacteria. Infect Immunol 1991; 59: 421-427.
102. Kunin C. Detection, prevention and management of urinary tract infections. Philadelphia, USA, Lea and Feiger, 1987.

103. Leffler H, Svanborg-Edén C. Chemical identification of a glycosphingolipid receptor for Escherichia coli attaching to human urinary tract epithelial cells and agglutinating human erythrocytes. FEMS Microbiol Lett 1980; 8: $127-134$.

104. Breimer M, Hansson G, Leffler H. The specific glycosphingolipid composition of human urethral epithelial cells. J Biochem 1985; 98: 1169-1180.

105. Lindberg F, Lund B, Normark S. Genes of pyelonephritogenic Escherichia coli required for digalactoside specific agglutination of human cells. EMBO $J$ 1984; 3: 1167-1173.

106. Marklund B. Structural and functional variation among Gal $\alpha 1-4 \mathrm{Gal} \beta$ adhesins of Escherichia coli. Thesis, University of Umeå, 1991.

107. Johanson I, Lindstedt R, Svanborg C. The role of the pap and prs encoded adhesins in Escherichia coli adherence to human epithelial cells. Infect Immun 1992; 60: 3416-3422.

108. Lindstedt R, Larson G, Falk P, Jodal U, Leffler H, Svanborg-Edén $\mathrm{C}$. The receptor repertoire defines the host range for attaching Escherichia coli recognizing globo-A. Infect Immun 1991; 59: 1086-1092.

109. Lund B, Marklund B-I, Strömberg N, Lindberg F, Karlsson K, Normark S. Uropathogenic Escherichia coli can express serologically identical pill of different receptorbinding specificities. Mol Microbiol 1988; 2: 255-263.

110. Strömberg N, Marklund B-I, Lund B, et al. Host-specificity of uropathogenic Escherichia coli depends on differences in binding specificity to Gal $\alpha-4 \mathrm{Gal} \beta$-containing isoreceptors. EMBO J 1990; 9: 2001-2010.

111. Krogfelt K, Bergmans H, Klemm P. Direct evidence that the FimH protein is the mannose-specific adhesin of Escherichia coli type 1 fimbriae. Infect Immun 1990; 58: 1995-1998.

112. Giampapa C, Abraham S, Chiang T, Beachey E. Isolation and characterization of a receptor for type 1 fimbriae of Escherichia coli from guinea-pig erythrocytes. J Biol Chem 1988; 263: 5362-5367.

113. Wold A, Mestecky J, Tomana M, et al. Secretory immunoglobulin-A carries oligosaccharide receptors for Escherichia coli type 1 fimbrial lectin. Infect Immun 1990; 58: 3073-3077.

114. Duguid J, Smith I, Dempster G, Edmunds P. Nonflagellar filamentous appendages ("fimbriae") and haemagglutinating activity in Bacterium coli. J Pathol Bacteriol 1955; 70: 335-348.

115. Bar-Shavit Z, Ofek I, Goldman G, Mirelman D, Sharon $\mathrm{N}$. Mannose residues on phagocytes as receptors for the attachment of Escherichia coli and Salmonella typhi. Biochem Biophys Res Commun 1977; 78: 455-460.

116. Ofek I, Mirelman D, Sharon N. Adherence of Escherichia coli to human mucosal cells mediated by mannose receptors. Nature 1977; 265: 623-625.

117. Sokurenko E, Courtney H, Abraham S, Klemm P, Hasty D. Functional heterogeneity of type 1 fimbriae of Escherichia coli. Infect Immun 1992; 60: 4709-4719.

118. Sokurenko E, Courtney H, Ohman D, Klemm P, Hasty D. FimH family of type 1 fimbriae adhesins: functional heterogeneity due to minor sequence variations among fimH genes. J Bacteriol 1994; 176: 748-755.

119. Hedges S, de Man P, Linder H, van Kooten C, SvanborgEdén C. Interleukin-6 is secreted by epithelial cells in response to Gram-negative bacterial challenge. In: Macdonald T, ed. Advances in Mucosal Immunology. 
International Conference of Mucosal Immunity, London, Kluwer, 1990; pp. 144-148.

120. Hedges S, Svensson M, Svanborg C. Interleukin-6 response of epithelial cell lines to bacterial stimulation in vitro. Infect Immun 1992; 60: 1295-1301.

121. Svensson M, Lindstedt R, Radin N, Svanborg C. Epithelial glycosphingolipid expression as a determinant of bacterial adherence and cytokine production. Infect Immun 1994; 62: 4404-4410.

122. Agace W, Hedges S, Ceska M, Svanborg C. IL-8 and the neutrophil response to mucosal Gram-negative infection. J Clin Invest 1993; 92: 780-785.

123. Agace W, Hedges S, Andersson U, Andersson J, Ceska M, Svanborg C. Selective cytokine production by epithelial cells following exposure to Escherichia coli. Infect Immun 1993; 61: 602-609.

124. Hedges S, Agace W, Svensson M, Sjögren A-C, Ceska $\mathrm{M}$, Svanborg C. Uroepithelial cells are a part of a mucosal cytokine network. Infect Immun 1994; 62: 2315-2321.

125. Hedlund M, Svensson M, Nilsson A, Duan R, Svanborg C. Role of the ceramide signalling pathway in cytokine responses to P fimbriated Escherichia coli. J Exp Med 1996; 183: 1037-1044.

126. Hedges S, Agace W, Svanborg C. Epithelial cytokine responses and mucosal cytokine networks. Trends Microbiol 1995; 3: 266-270.

127. Massion PP, Inoue H, Richman-Eisenstat J, et al. Novel Pseudomonas product stimulates interleukin- 8 production in airway epithelial cells in vitro. J Clin Invest 1994; 93: 26-32.

128. DiMango E, Zar H, Bryan R, Prince A. Diverse $P$. aeroginosa gene products stimulate respiratory epithelial cells to produce IL-8. J Clin Invest 1995; 96: 2204-2210.

129. Eckmann L, Kagnoff MF, Fierer J. Epithelial cells secrete the chemokine interleukin-8 in response to bacterial entry. Infect Immun 1993; 61: 4569-4574.

130. Huang J, O'Toole P, Doig P, Trust T. Stimulation of interleukin-8 production in epithelial cell lines by Helicobacter pylori. Infect Immun 1995; 63: 1732-1738.

131. Sharma S, Tummuru M, Miller G, Blaser M. Interleukin-8 response of gastric epithelial cell lines to Helicobacter pylori stimulation in vitro. Infect Immun 1995; 63: 1681-1687.

132. Standiford T, Kunkel S, Basha M, et al. Interleukin-8 gene expression by a pulmonary epithelial cell line: a model for cytokine networks in the lung. J Clin Invest 1990; 86: 1945-1953.

133. Crestani B, Cornillet P, Dehoux M, Rolland C, Guenounou M, Aubier M. Alveolar type II epithelial cells produce interleukin 6 in vitro and in vivo. J Clin Invest 1994; 94: 731-740.

134. Pugin J, Schürer M, Leturcq D, Moriarty A, Ulevitch RJ, Tobias PS. Lipopolysaccharide activation of human endothelial and epithelial cells is mediated by lipopolysaccharide-binding protein and soluble CD14. Proc Natl Acad Sci 1993; 90: 2744-2748.

135. Anderson P, Engberg I, Lidin-Janson G, et al. Persistence of Escherichia coli bacteriuria is not determined by bacterial adherence. Infect Immun 1991; 59: 2915-2921.

136. Ko YC, Mukaida N, Ishiyama S, et al. Elevated interleukin-8 levels in the urine of patients with urinary tract infections. Infect Immun 1993; 61: 1307-1314.

137. Benson M, Jodal U, Agace $\mathrm{W}$, et al. Interleukin-6 and interleukin-8 in children with febrile urinary tract infection and asymptomatic bacteriuria. J Infect Dis 1996; (in press).
138. Tullus K, Fituri O, Burman L, Wretlind B, Brauner A. Interleukin- 6 and interleukin- 8 in the urine of children with acute pyelonephritis. Pediatr Nephrol 1994; 8: 280-284.

139. Oishi K, Sonoda F, Kobayashi S, et al. Role of IL-8 and an inhibitory effect of erythromycin on IL-8 release in the airways of patients with chronic airway diseases. Infect Immun 1994; 62: 4145-4152.

140. Crabtree JE, Wyatt JI, Trejdosiewicz LK, et al. Interleukin-8 expression in Helicobacter pylori infected, normal, and neoplastic gastroduodenal mucosa. J Clin Pathol 1994; 47: 61-66.

141. Raqib R, Lindberg A, Wretlind B, Bardhan P, Andersson U, Andersson J. Persistence of local cytokine production in shigellosis in acute and convalescent stages. Infect Immun 1995; 63: 289-296.

142. Agace W, Patarroyo M, Svensson M, Carlemalm E, Svanborg C. Escherichia coli induce transuroepithelial neutrophil migration by an ICAM-1 dependent mechanism. Infect Immun 1995; 63: 4045-4062.

143. Agace W, Godaly G, Proudfoot A, Hedges S, Svanborg C. Escherichia coli induced transepithelial migration is IL-8 dependent. (Submitted).

144. Richtman-Eisenstat J, Jorens P, Hébert C, Ueki I, Nadel J. Interleukin-8: an important chemoattractant in sputum of patients with chronic inflammatory airway disease. Am J Physiol 1993; 264: L413-L418.

145. Tosi M, Stark J, Hemedani A, Gruenert D, Infeld M. Induction of ICAM-1 expression on human airway epithelial cells by inflammatory cytokines: effects on neutrophil-epithelial cell adhesion. Am J Respir Cell Mol Biol 1992; 7: 214-221.

146. Kvale D, Krajci P, Brandtzaeg P. Expression and regulation of adhesion molecules ICAM-1 (CD54) and LFA-3 (CD58) in human intestinal epithelial cell lines. Scand J Immunol 1992; 35: 669-676.

147. Hill P, Lan H, Nikolic-Paterson D, Atkins R. Pulmonary expression of ICAM-1 and LFA-1 in experimental Goodpasture's syndrome. Am J Pathol 1994; 145: 220-227.

148. Ishikura H, Takahashi $\mathrm{C}$, Kanagawa K, Hirata H, Imai $\mathrm{K}$, Yoshiki T. Cytokine regulation of ICAM-1 expression on human renal tubular epithelial cells in vitro. Transplantation 1991; 51: 1272-1275.

149. Jackson A, Alexandrov A, Prescott S, James K, Chisholm G. Expression of adhesion molecules by bladder cancer cells: modulation by interferon-gamma and tumour necrosis factor. J Urol 1992; 148: 1583-1586.

150. Elgavish A. Effects of Escherichia coli and E. coli LPS on the function of human ureteral epithelial cells cultured in serum-free medium. Infect Immnun 1993; 61: 3304-3312.

151. Liebert M, Wedemeyer G, Stein J, et al. Evidence for urothelial cell activation in interstitial cystitis. J Immunol 1993; 149: 470-475.

152. Bruijn J, Dinklo N. Distinct patterns of expression of intercellular adhesion molecule-1, vascular cell adhesion molecule-1, and endothelial-leukocyte adhesion molecule-1 in renal disease. Lab Invest 1993; 69: 329-335.

153. Minervini R, Panichi V, Vigano L, et al. Cellular expression of lymphocyte function antigen-1 and intercellular adhesion molecule-1 in normal kidney structures and in renal cancer. Eur Urol 1994; 26: 103-106.

154. Bechtel U, Scheur R, Landgraf R, König A, Feucht H. Assessment of soluble adhesion molecules (sICAM-1, sVCAM-1, sELAM-1) and complement cleavage products (sC4d, sC5b-9) in urine. Transplantation 1994; 58: 905-911. 
155. Jackson A, Alexandroff A, McIntyre M, Esuvaranathan $\mathrm{K}$, James K, Chisholm G. Induction of ICAM-1 expression on bladder tumours by BCG immunotherapy. $J$ Clin Pathol 1994; 47: 309-312.

156. Hagberg L, Hull R, Hull S, McGhee JR, Michalek SM, Svanborg-Eden C. Difference in susceptibility to Gram-negative urinary tract infection between $\mathrm{C} 3 \mathrm{H} /$ $\mathrm{HeJ}$ and $\mathrm{C} 3 \mathrm{H} / \mathrm{HeN}$ mice. Infect Immun 1984; 46: 839-844.

157. de Man P, Van Kooten C, Aarden L, Engberg I, SvanborgEdén C. Interleukin-6 induced by Gram-negative bacterial infection at mucosal surfaces. Infect Immun 1989; 57: 3383-3388.

158. Barber S, Perera P, Vogel S. Defective ceramide response in $\mathrm{C} 3 \mathrm{H} / \mathrm{HeJ}$ (Lpsd) macrophages. J Immunol 1995; 155 : 2302-2305.

159. Agace W, Hedges S, Svanborg C. Lps genotype in the C57 black mouse background and its influence on the interleukin-6 response to $E$. coli urinary tract infection. Scand J Immunol 1997; 35: 531-538.

160. Linder H, Engberg I, van Kooten C, de Man P, SvanborgEdén C. Effects of anti-inflammatory agents on mucosal inflammation induced by Gram-negative infection. Infect Immun 1990; 58: 2056-2060.

161. Miller T, Findon G, Cawley S. Cellular basis of host defence in pyelonephritis. III. Deletion of individual components. Br J Exp Path 1987; 68: 377-388. 